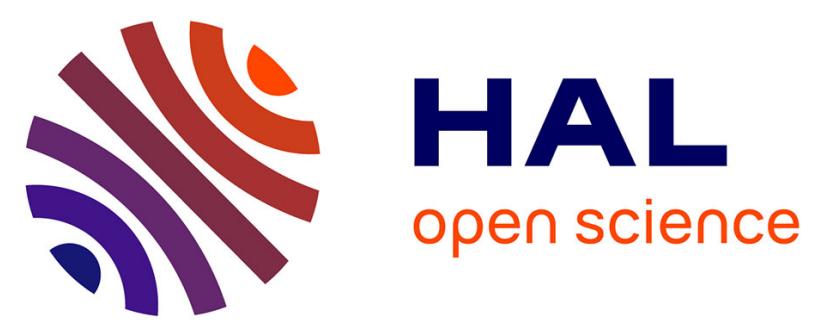

\title{
Buoyancy Effects in the Turbulence Kinetic Energy Budget and Reynolds Stress Budget for a Katabatic Jet over a Steep Alpine Slope
}

Claudine Charrondière, Christophe Brun, Jean-Emmanuel Sicart, Jean-Martial Cohard, Romain Biron, Sébastien Blein

\section{To cite this version:}

Claudine Charrondière, Christophe Brun, Jean-Emmanuel Sicart, Jean-Martial Cohard, Romain Biron, et al.. Buoyancy Effects in the Turbulence Kinetic Energy Budget and Reynolds Stress Budget for a Katabatic Jet over a Steep Alpine Slope. Boundary-Layer Meteorology, 2020, 177 (1), pp.97-122. 10.1007/s10546-020-00549-2 . hal-03124731

\section{HAL Id: hal-03124731 \\ https://hal.science/hal-03124731}

Submitted on 23 Aug 2021

HAL is a multi-disciplinary open access archive for the deposit and dissemination of scientific research documents, whether they are published or not. The documents may come from teaching and research institutions in France or abroad, or from public or private research centers.
L'archive ouverte pluridisciplinaire HAL, est destinée au dépôt et à la diffusion de documents scientifiques de niveau recherche, publiés ou non, émanant des établissements d'enseignement et de recherche français ou étrangers, des laboratoires publics ou privés.

\section{(c)(1)}

Distributed under a Creative Commons Attribution| 4.0 International License 


\title{
Buoyancy Effects in the Turbulence Kinetic Energy Budget and Reynolds Stress Budget for a Katabatic Jet over a Steep Alpine Slope
}

\author{
Claudine Charrondière ${ }^{1,2}$ (D) Christophe Brun $^{1} \cdot$ Jean-Emmanuel Sicart ${ }^{2}$. \\ Jean-Martial Cohard ${ }^{2} \cdot$ Romain Biron ${ }^{2}$ Sébastien Blein ${ }^{1,3}$
}

\begin{abstract}
Katabatic winds are very frequent but poorly understood or simulated over steep slopes. This study focuses on a katabatic jet above a steep alpine slope. We assess the buoyancy terms in both the turbulence kinetic energy (TKE) and the Reynolds shear-stress budget equations. We specifically focus on the contribution of the slope-normal and along-slope turbulent sensible heat fluxes to these terms. Four levels of measurements below and above the maximum windspeed height enable analysis of the buoyancy effect along the vertical profile as follow: (i) buoyancy tends to destroy TKE, as expected in stable conditions, and the turbulent momentum flux in the inner-layer region of the jet below the maximum wind-speed height $z_{j}$; (ii) results also suggest buoyancy contributes to the production of TKE in the outer-layer shear region of the jet (well above $z_{j}$ ) while consumption of the turbulent momentum flux is observed in the same region; (iii) In the region around the maximum wind speed where mechanical shear production is marginal, buoyancy tends to destroy TKE and our results suggest it tends to increase the momentum flux. The present study also provides an analytical condition for the limit between production and consumption of the turbulent momentum flux due to buoyancy as a function of the slope angle, similar to the condition already proposed for TKE. We reintroduce the stress Richardson number, which is the equivalent of the flux Richardson number for the Reynolds shear-stress budget. We point out that the flux Richardson number and the stress Richardson number are complementary stability parameters for characterizing the katabatic flow apart from the region around the maximum wind-speed height.
\end{abstract}

Keywords Buoyancy production - Flux and stress Richardson numbers - Katabatic jets . Steep alpine slope $\cdot$ Turbulence kinetic energy

Claudine Charrondière

charrondiere.claudine@gmail.com

1 Laboratoire des Écoulements Géophysiques et Industriels (LEGI), Grenoble, France

2 Institut des Géosciences de l'Environnement (IGE), Grenoble, France

3 Centre National de Recherches Météorologiques (CNRM), Toulouse, France 


\section{Introduction}

Katabatic winds are gravity flows that develop over sloping terrain due to radiative cooling at the surface. They generally are responsible for night circulation near the surface and bring cold air down the valleys, thereby enhancing the temperature inversion and trapping pollutants (Whiteman 2000).

Katabatic jets occur close to the surface over mountain slopes at a scale ranging from a few tens of metres in depth (Nadeau et al. 2013a, b; Grachev et al. 2016; Blein 2016) to about a hundred metres (e.g., Smeets et al. 1998; Monti et al. 2002; Poulos and Zhong 2008). For steep slopes of more than $20^{\circ}$, the maximum wind-speed height can be as low as $1 \mathrm{~m}$ (Horst and Doran 1988; Oldroyd et al. 2014). Such flows are inadequately represented in most meteorological models, with poor resolution close to the surface. Consequently, models fail in predicting weather and pollution events often associated with katabatic events or downslope flow in winter with anticyclonic conditions (Low 1990; Largeron 2010; Largeron and Staquet 2016). Extending our understanding of katabatic flows is therefore a major challenge to improving mountain weather forecasts and mitigating the risk of this type of pollution for public health.

Although according to Poulos and Zhong (2008), katabatic flows have been studied since the 1840s, experimental works have generally drawn on measurements made over gentle slopes (e.g., Smeets et al. 1998; Monti et al. 2002; Litt et al. 2015; Grachev et al. 2016; Jensen et al. 2017, and references therein). Horst and Doran (1988) were among the first to study katabatic winds over a steep slope $\left(21^{\circ}\right)$ followed more recently by Nadeau et al. (2013a), Stiperski and Rotach (2016) and Oldroyd et al. (2016a). Nadeau et al. (2013a) focused on the establishment of the katabatic flow when the sun disappears behind the mountain, and on the evolution of the partitioning between the terms of the turbulence kinetic energy (TKE) budget. Stiperski and Rotach (2016) studied the differences between post-processing methods in the context of mountainous terrain, which is far from the classical hypotheses of flat and homogeneous surfaces. Oldroyd et al. (2016a) focused on the effect of the slope angle on the production/consumption of TKE caused by buoyancy. Indeed, over steep slopes, the slope-normal and the vertical components of the turbulent sensible heat flux may differ significantly. This suggests a change in the behaviour of what is referred to as the buoyancy production term in the TKE budget equation over steep slopes compared with gentle slopes. Denby (1999) even introduced a critical angle $\left(\approx 25^{\circ}\right)$ above which behaviour changes.

Concerning numerical results, a few large-eddy simulation (LES) or direct numerical simulation (DNS) models have been used to study katabatic jets (e.g., Axelsen and van Dop $2009 \mathrm{a}, \mathrm{b})$ along angle slopes lower than $10^{\circ}$, and references therein). Along steep slopes of more than $20^{\circ}$, most LES and DNS studies were performed in a periodic configuration along the slope (Fedorovich and Shapiro 2009; Burkholder et al. 2011; Giometto et al. 2017), which relies on the transposition of the idealized Prandtl model (Prandtl 1942) to turbulent flow configuration. In such cases, homogeneous streamwise conditions lead to a cancellation of longitudinal gradients and may affect the streamwise heat flux and thus the buoyancy effect in the TKE budget equation. Large-eddy simulation of spatially evolving katabatic jets was investigated by Skyllingstad (2003), Smith and Skyllingstad (2005), and Smith and PortéAgel (2014). Smith and Skyllingstad (2005) concentrated on the variation of strength of the flow due to the modification of the slope angle along the longitudinal direction. Brun et al. (2017) also applied LES to a steep curved slope and showed that the streamwise heat flux could play an important role in buoyancy production of TKE. 
Most meteorological models rely on the Monin-Obukhov similarity theory (MOST) via stability parameters such as the Obukhov length or Richardson number to describe the way turbulence is modified by stratification (Wyngaard 2010). Generally, MOST is designed for a terrain that is assumed to be flat and homogeneous, which leads to a constant-vertical-flux layer approximation. As an example, Denby and Smeets (2000) show that for katabatic flows on a glacier surface, momentum fluxes increase with the height in the region beneath the wind maximum. They further derived the vertical momentum-flux profile by integrating the temperature deficit from momentum budget balance between katabatic forcing and vertical flux divergence. This implies that the momentum flux may not be constant in a katabatic jet along a slope and thus MOST may not be valid. Grisogono et al. (2007) explain that the Obukhov length is not appropriate as long as the slope is not negligible (more than $5^{\circ}$ ), since the buoyancy contribution has a component in the along-slope direction. The impact of slope on Obukhov length, flux, and gradient Richardson numbers is analyzed in Oldroyd et al. (2016a). They conclude that the Obukhov length changes behaviour depending whether defined with the slope-normal or the vertical turbulent buoyancy flux. The sign of the flux Richardson number $R_{f}$, which relies on the sign of both the mechanical shear and buoyancy terms, was also shown to be sensitive depending on its definition, leading to either production or consumption of TKE along the vertical profile. In particular, they mention a possible negative value for a critical Richardson number in the outer layer above the maximum wind speed. However, they note that the change in behaviour of $R_{f}$ remains less pronounced than for the Obukhov length.

The TKE budget can be complemented by the Reynolds shear-stress budget to describe turbulent properties. This budget involves production terms that are also related to mechanical and buoyancy contributions. Their ratio is used to design what is called the stress Richardson number $R_{S}$ (Bradshaw 1969; Wyngaard et al. 1971), which involves the horizontal turbulent sensible heat flux and may provide a complementary view of the stability analysis of the flow. To our knowledge, the stress Richardson number $R_{S}$ has never been used to describe a katabatic jet.

The study of both TKE and shear stress allows an analysis in terms of turbulence anisotropy (e.g., Pope 2000, for simple neutral shear flows). In most cases, velocity variances are not isotropic, and the main shear stress contribution cannot be neglected. When stratified turbulence is considered, buoyancy production is added to mechanical production and distorts the relaxation process towards isotropic state (Krug et al. 2013) by decreasing slope-normal velocity fluctuations (Krug et al. 2017). This complex process is expected for flows submitted to strong shear and to buoyancy forces such as katabatic jets.

In this study, we analyze a katabatic flow that developed on a steep slope of more than $20^{\circ}$ in the Belledonne Massif (French Alps, Blein 2016). We take advantage of measurements taken at four levels along the mast on both sides of the jet maximum to deepen the existing experimental analysis of turbulence in katabatic flows (Horst and Doran 1988; Nadeau et al. 2013a; Oldroyd et al. 2016a; Stiperski and Rotach 2016, who focused on the outer-layer region of the jet).

The paper is organized in four sections. Section 2 presents a theoretical background, white Sect. 3 describes the experimental site and the dataset used, as well as data post-processing. Section 4 focuses on turbulence anisotropy and characteristics of the flows, as well as on the buoyancy term in both the TKE budget and the Reynolds stress budget. In Sect. 4, we also analyze the profiles of the flux Richardson number and the stress Richardson number in the katabatic flow and discuss whether these parameters are meaningful in the context of a katabatic jet over steep slopes. Finally, in Sect. 5, we summarize results. 


\section{Theory}

\subsection{Turbulence Kinetic Energy Budget and Flux Richardson Number}

The TKE budget is written as

$$
\underbrace{D_{t} e}_{\substack{\mathrm{TKE} \\
\text { spatio-temporal } \\
\text { variability }}}=\underbrace{P_{B}^{e}}_{\substack{\text { Buoyancy } \\
\text { production/consumption }}}+\underbrace{P_{M}^{e}}_{\begin{array}{c}
\text { Mechanical } \\
\text { production/consumption }
\end{array}}+\underbrace{T T^{e}}_{\substack{\text { Turbulent } \\
\text { transport }}}-\underbrace{\epsilon^{e}}_{\text {Dissipation }},
$$

where $e=\frac{1}{2}\left(\overline{u^{\prime 2}}+\overline{v^{\prime 2}}+\overline{w^{\prime 2}}\right)$ is the TKE (e.g., see Pope 2000; Stull 1988, without/with buoyancy respectively); $\overline{(\cdot)}$ represents temporal averaging and $(\cdot)^{\prime}$ is used for fluctuations around the average value following Reynolds decomposition. $u, v$ and $w$ are the along-slope, spanwise, and slope-normal wind velocity components, respectively, in a coordinate system following the slope (Fig. 1). Over a slanted terrain of angle $\alpha, u_{z}$ and $w_{z}$ are the horizontal and vertical velocity components, respectively, in a coordinate system aligned with gravity.

The term $D_{t} e$ is the material derivative of the TKE. It contains both the temporal tendency and the advection of TKE. $T T^{e}$ merges the turbulent transport term and the pressure transport term, which are not under the scope of this experimental study, although the latter has been shown to transport TKE down toward the wall (Giometto et al. 2017). This effect is expected to act very close to the ground, below the region of the maximum of wind speed, which is out of access for the present experimental study. Also note that there is no direct way to determine it experimentally, to date.

In a statistically two-dimensional homogeneous flow with respect to the spanwise $y_{n}$ direction (e.g., Pope 2000), turbulent fluxes involving $v^{\prime}$ component cancel due to symmetry with respect to the mean shear plane $\left(\mathbf{x}_{\mathbf{n}}, \mathbf{z}_{\mathbf{n}}\right)$. That is the case for the Reynolds turbulent stresses $\overline{u^{\prime} v^{\prime}}$ and $\overline{v^{\prime} w^{\prime}}$, and for the spanwise turbulent heat flux $\overline{v^{\prime} \theta^{\prime}}$. This configuration

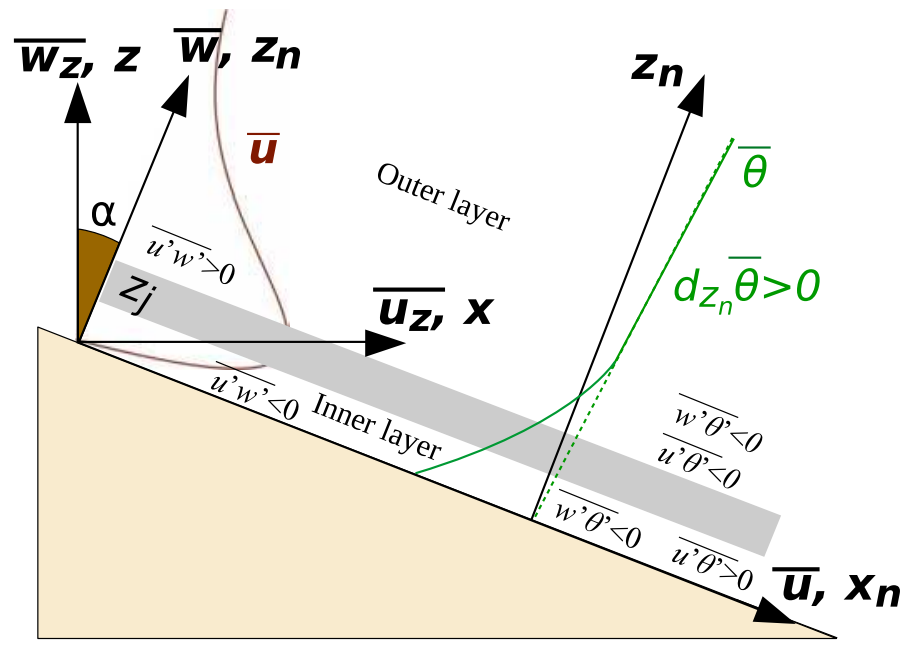

Fig. 1 Schematic of the slope coordinate system used in the present study. $z$ represents the component aligned with gravity and $z_{n}$ is normal to the ground surface. $(u, w)$ is expressed in the slope referential $\left(\mathbf{x}_{\mathbf{n}}, \mathbf{z}_{\mathbf{n}}\right) . \alpha$ is the slope angle. In our dataset, the height of maximum wind speed $z_{j}$ is located between 1 and $2 \mathrm{~m}$. The grey zone is the region around the maximum wind speed that separates the outer and the inner layers of the jet 
corresponds to the case of a pure katabatic jet along a slope upon which we intend to focus. This is exactly valid in the case of DNS (e.g., Giometto et al. 2017) or LES (e.g., Brun 2017) for katabatic flows along a two-dimensional slope.

With these pure katabatic two-dimensional assumptions, the buoyancy term in the TKE budget reduces to (e.g., Horst and Doran 1988)

$$
P_{B}^{e}=\frac{g}{\bar{\theta}} \overline{w_{z}^{\prime} \theta^{\prime}}=\frac{g}{\bar{\theta}}\left(\overline{w^{\prime} \theta^{\prime}} \cos \alpha-\overline{u^{\prime} \theta^{\prime}} \sin \alpha\right)
$$

and defined in the slope coordinate system as in Fig. 1, with $\mathbf{x}_{\mathbf{n}}$ directed downslope.

The quantity $\theta$ is the atmospheric potential temperature. The buoyancy production of TKE splits into two components. One expresses the production/consumption of TKE by the sensible heat flux normal to the surface. The second represents the production/consumption of TKE associated with the along-slope sensible heat flux. Their respective magnitudes are weighted by a slope-dependent coefficient, and their effect on the TKE budget relies on the sign of both heat fluxes $\overline{w^{\prime} \theta^{\prime}}$ and $\overline{u^{\prime} \theta^{\prime}}$. Equation 2 shows that the steeper the surface the greater is the relative contribution of $\overline{u^{\prime} \theta^{\prime}}$.

In the case of the pure katabatic jet described above, the off-diagonal terms of the Reynolds stress tensor reduce to the turbulent shear stress $\overline{u^{\prime} w^{\prime}}$. Thus, the main contribution to TKE mechanical production is written as (e.g., Nadeau et al. 2013a)

$$
P_{M}^{e} \approx-\overline{u^{\prime} w^{\prime}} \partial_{z_{n}} \bar{u},
$$

where $\partial_{z_{n}} \bar{u}$ is the slope-normal gradient of average wind speed. Equation 3 is a reduction of the full mechanical term for a pure katabatic jet configuration, with no spanwise contribution, no normal entrainment, and negligible streamwise variability.

Figure 1 shows two distinct regions along the slope-normal axis in the jet, one below the region of the maximum wind-speed height $z_{j}$ and one above it. Below (above) $z_{j}$, the mean velocity gradient $\partial_{z_{n}} \bar{u}$ is positive (negative). For the present katabatic jet, the Boussinesq hypothesis (Eq. 4) for the definition of eddy viscosity $K_{m}$ (Boussinesq 1877, cited in Pope 2000) holds below and above the maximum wind-speed height as far as each of the two regions unveils a turbulent shear flow,

$$
\overline{u^{\prime} w^{\prime}}=-K_{m} \partial_{z_{n}} \bar{u}
$$

This relation is known to fail in the region where the mean shear goes to zero (e.g., Brun et al. 2017; Giometto et al. 2017), which may lead to consumption of TKE ( $\left.P_{M}^{e}<0\right)$ around the maximum wind-speed height. Elsewhere, we expect to observe $\overline{u^{\prime} w^{\prime}}<0$ below $z_{j}$ and $\overline{u^{\prime} w^{\prime}}>0$ above it, leading to TKE production $P_{M}^{e}>0$.

The sign of the slope-normal and along-slope turbulent sensible heat fluxes is described in Grachev et al. (2016) in the theoretical case of a stable turbulent jet and in Fig. 2 in Łobocki (2017) for a boundary layer. It is also observed in Stiperski et al. (2020) for a katabatic jet : $\overline{w^{\prime} \theta^{\prime}}<0$ everywhere in the jet; $\overline{u^{\prime} \theta^{\prime}}$ is positive below $z_{j}$ and $\overline{u^{\prime} \theta^{\prime}}$ negative above it.

Horst and Doran (1988) and Denby (1999) introduced the condition in which buoyancy production of TKE occurs (Eq. 5). This condition corresponds to $P_{B}^{e}>0$ in Eq. 2. Note that this condition, Eq. 5, is valid only if the slope-normal turbulent sensible heat flux $\overline{w^{\prime} \theta^{\prime}}$ is negative, as is the case at night in anticyclonic conditions and more generally in stable cases

$$
\frac{\overline{\overline{u^{\prime} \theta^{\prime}}}}{\overline{w^{\prime} \theta^{\prime}}}>\cot \alpha \text {. }
$$

Over a steep slope of $35.5^{\circ}$, Oldroyd et al. (2016a) showed that this condition can occur above the jet maximum height. However, not enough observations were available to generalize 
their conclusion so far. Horst and Doran (1988) first observed in a modelling approach that above the jet maximum, TKE production approaches zero at about $\alpha=30^{\circ}$, with a trend that implies a change of sign of $P_{B}^{e}$, and thus a shift from TKE consumption to TKE production for higher slope angles. Denby (1999), who used the above condition in his numerical study, set a constant value of 2.1 for the ratio of sensible heat fluxes (i.e., defining a critical angle $\alpha_{c}=25^{\circ}$ above which TKE is produced by buoyancy and below which buoyancy destroys TKE). However, observations show that these fluxes vary considerably, and their ratio is not constant (Grachev et al. 2016; Oldroyd et al. 2016a). A universal and physical threshold value of slope angle does not exist, but it remains valid that the steeper the slope the more important is the impact of the along-slope heat flux.

Two parameters are commonly used to quantify stability: the Obukhov length and the flux Richardson number. In stratified boundary layers, Nieuwstadt (1984) observed that the magnitude of fluxes varies significantly with height, and proposed local scaling to define a more appropriate parameter using fluxes at each measurement level instead of surface fluxes. The Obukhov length $L$, even in its local form, has been designed for a stable atmospheric boundary layer $(\mathrm{ABL})$ on a flat terrain and is hard to define properly on slope reference axes (Grisogono et al. 2007; Oldroyd et al. 2016a). We presently focus on the flux Richardson number $R_{f}$, defined in Eq. 6 (Stull 1988) because it represents the ratio between the buoyancy and the mechanical shear terms that serve as source or sink in the TKE budget (Eq. 1),

$$
R_{f}=-\frac{P_{B}^{e}}{P_{M}^{e}}=\frac{(g / \bar{\theta}) \overline{w_{z}^{\prime} \theta^{\prime}}}{\overline{u^{\prime} w^{\prime}} \partial_{z_{n}} \bar{u}} .
$$

In a wall jet flow, the inner layer behaves like a turbulent boundary layer, with $P_{M}^{e}>0$. This means that the sign of $R_{f}$ depends only on the sign of $-P_{B}^{e}$, and enables a direct interpretation of $R_{f}$ in the inner layer of a katabatic flow. For the outer layer of the jet, the gradient of wind velocity $\partial_{z_{n}} \bar{u}$ is negative, but $P_{M}^{e}$ is still positive due to a positive turbulent momentum flux. In this case, the interpretation of $R_{f}$ is the same as for the inner layer of the jet and for a classical turbulent boundary layer. Finally, $\partial_{z_{n}} \bar{u}$ is poorly defined and close to zero in the region of the maximum wind speed. In the present case, $P_{M}^{e}$ is slightly negative and $R_{f}$ is driven by the buoyancy term $P_{B}^{e}$.

\subsection{Reynolds Shear Stress Budget and Stress Richardson Number}

As described in Sect. 2.1, in a statistically two-dimensional homogeneous katabatic jet, the only resulting turbulent stress is $\overline{u^{\prime} w^{\prime}}\left(=\operatorname{sign}\left(\overline{u^{\prime} w^{\prime}}\right)\left|\overline{u^{\prime} w^{\prime}}\right|\right)$. Its sign changes from negative to positive in the region around the jet maximum height. Its budget is given in Eq. 7 (e.g., Wyngaard et al. (1971); Horst and Doran (1988) with buoyancy, and Pope (2000) without buoyancy). Note that Eq. 7 corresponds to the standard formulation of the $\overline{u^{\prime} w^{\prime}}$ budget once multiplied by $\operatorname{sign}\left(\overline{u^{\prime} w^{\prime}}\right)$. The present formulation makes it possible to discuss the magnitude of $\overline{u^{\prime} w^{\prime}}$, whatever its sign, below and above the jet maximum. Thus $P_{M}^{S}>0$ or $P_{B}^{s}>0$ contributes to an increase of $\left|\overline{u^{\prime} w^{\prime}}\right|$ (production) and $P_{M}^{S}<0$ or $P_{B}^{S}<0$ contributes to a decrease of $\left|\overline{u^{\prime} w^{\prime}}\right|$ (consumption),

$$
\underbrace{D_{t}\left|\overline{u^{\prime} w^{\prime}}\right|}_{\begin{array}{c}
\text { Turbulent } \\
\text { shear-stress } \\
\text { variability }
\end{array}}=\underbrace{P_{M}^{s}}_{\begin{array}{c}
\text { Mechanical } \\
\text { production or } \\
\text { consumption }
\end{array}}+\underbrace{P_{B}^{s}}_{\begin{array}{c}
\text { Buoyancy } \\
\text { production or } \\
\text { consumption }
\end{array}}+\underbrace{T T^{s}}_{\begin{array}{c}
\text { Stress turbulent } \\
\text { transport }
\end{array}}-\underbrace{\epsilon^{s}}_{\begin{array}{c}
\text { Stress } \\
\text { dissipation }
\end{array}} .
$$




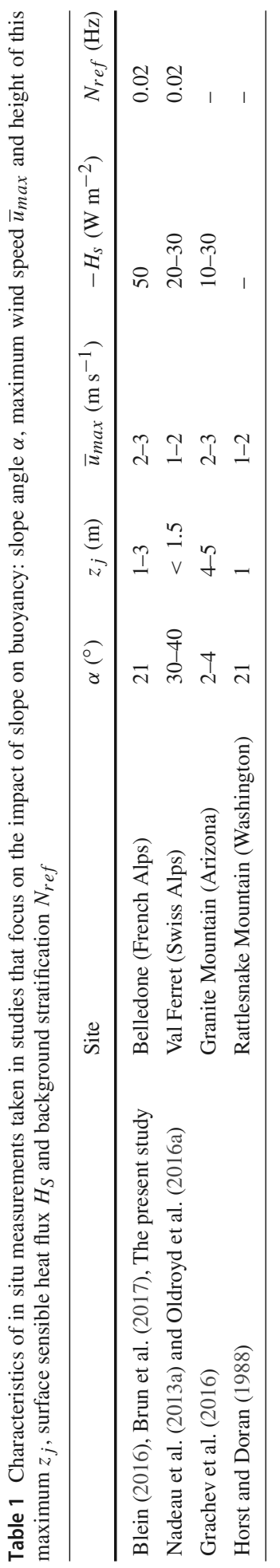


The buoyancy and mechanical terms are given by Eqs. 8 and 9, respectively,

$$
\begin{aligned}
& \operatorname{sign}\left(\overline{u^{\prime} w^{\prime}}\right) P_{B}^{s}=\frac{g}{\bar{\theta}} \overline{u_{z}^{\prime} \theta^{\prime}}=\frac{g}{\bar{\theta}}\left(\overline{u^{\prime} \theta^{\prime}} \cos \alpha+\overline{w^{\prime} \theta^{\prime}} \sin \alpha\right), \\
& \operatorname{sign}\left(\overline{u^{\prime} w^{\prime}}\right) P_{M}^{s}=-\overline{w^{\prime 2}} \partial_{z_{n}} \bar{u} .
\end{aligned}
$$

Bradshaw (1969) suggested using the ratio between the two production terms to design a so-called stress Richardson number $R_{s}$ (Eq. 10), complementary to $R_{f}$ (Eq. 6),

$$
R_{s}=-\frac{P_{B}^{s}}{P_{M}^{s}}=\frac{(g / \bar{\theta}) \overline{u_{z}^{\prime} \theta^{\prime}}}{\overline{w^{\prime 2}} \partial_{z_{n}} \bar{u}} .
$$

Wyngaard et al. (1971) observed that $R_{S} / R_{f}=\left(\overline{u_{z}^{\prime} \theta^{\prime}} / \overline{w_{z}^{\prime} \theta^{\prime}}\right)\left(\overline{u^{\prime} w^{\prime}} / \overline{w^{\prime 2}}\right)$ is about 2 in neutral conditions, drops rapidly to zero for unstable conditions such as vertical convection, and is close to 1 for stable conditions over a flat terrain. To our knowledge, $R_{S}$ has never been studied in katabatic jets, even though the turbulent fluxes involved are of interest in a katabatic flow and far from negligible (Oldroyd et al. 2016a).

The condition in which buoyancy production of $\left|\overline{u^{\prime} w^{\prime}}\right|$ occurs can be designed from Eq. 8 and is written as Eq. 11, when $\overline{w^{\prime} \theta^{\prime}}<0$,

$$
\operatorname{sign}\left(\overline{u^{\prime} w^{\prime}}\right) \times \frac{\overline{u^{\prime} \theta^{\prime}}}{\overline{w^{\prime} \theta^{\prime}}}<-\tan \alpha \times \operatorname{sign}\left(\overline{u^{\prime} w^{\prime}}\right) .
$$

Thus, above and below the jet maximum, production of momentum flux occurs following

$$
\begin{aligned}
& \overline{\overline{w^{\prime} \theta^{\prime}}}<-\tan \alpha \quad \text { if } \overline{u^{\prime} w^{\prime}}>0, \\
& \overline{\overline{w^{\prime} \theta^{\prime}}}>-\tan \alpha \quad \text { if } \overline{u^{\prime} w^{\prime}}<0 \text {. }
\end{aligned}
$$

\subsection{Turbulence Anisotropy}

The normalized anisotropy tensor is defined (e.g., Pope 2000) based on the Reynolds stress tensor and TKE by Eq. 13,

$$
a_{i j}=\frac{\overline{u_{i}^{\prime} u_{j}^{\prime}}}{2 e}-\frac{\delta_{i j}}{3},
$$

$\delta_{i j}$ being the Kronecker symbol. The anisotropy coefficient $F$ (Eq. 14) is derived from $I_{2}$ and $I_{3}$, the second and the third invariants of $a_{i j}$ respectively (Lumley 1979),

$$
F=1+9 I_{2}+27 I_{3}=1-\frac{9}{2} a_{i j} a_{j i}+9 a_{i j} a_{j k} a_{k i}
$$

For homogeneous isotropic turbulence, the Reynolds stress tensor is diagonal with normal stresses $\overline{u^{\prime 2}}=\overline{v^{\prime 2}}=\overline{w^{\prime 2}}$ equal to the isotropic value $\frac{2}{3} e$ (e.g., Pope 2000). There, the anisotropy coefficient reduces to $F=1$. For a pure katabatic jet as defined in Sect. 2.1, as a statistically two-dimensional homogeneous flow with respect to the spanwise $\mathbf{y}_{\mathbf{n}}$ direction, the anisotropy coefficient $F$ reduces to Eq. 15. There, we neglect the third invariant $I_{3}$ contribution with respect to the second invariant $I_{2}$. The second invariant is expected to be the more relevant for the determination of $F$ since it represents the degree of anisotropy (e.g., 
Table 2 Heights of sensors on the measurement mast $z_{n}$ is the slope-normal height. $T_{\text {sonic }}$ stands for sonic temperature, $T$ for temperature, and $R H$ for relative humidity

\begin{tabular}{lllll}
\hline Level & Sensor & $z_{n}(\mathrm{~m})$ & Variables measured & Frequency $(\mathrm{Hz})$ \\
\hline $\mathrm{a}$ & KT15 & 0 & $T$ & 0.5 \\
1 & CSAT3 & 1.00 & $u, v, w, T_{\text {sonic }}$ & 20 \\
$\mathrm{~b}$ & CS215 & 1.59 & $R H, T$ & 0.5 \\
2 & CSAT3 & 1.77 & $u, v, w, T_{\text {sonic }}$ & 20 \\
$\mathrm{c}$ & WindSonic & 3.08 & $u, v$ & 0.5 \\
3 & CSAT3 & 3.98 & $u, v, w, T_{\text {sonic }}$ & 20 \\
4 & WindMaster Pro & 6.31 & $u, v, w, T_{\text {sonic }}$ & 10 \\
\hline
\end{tabular}

Brun 2017; Brugger et al. 2018; Stiperski et al. 2020),

$$
F \approx 1-\frac{9}{8}\left[\left(\frac{\overline{u^{\prime} w^{\prime}}}{e}\right)^{2}+\left(\frac{\overline{u^{\prime 2}}-\frac{2}{3} e}{e}\right)^{2}+\left(\frac{\overline{w^{\prime 2}}-\frac{2}{3} e}{e}\right)^{2}+\left(\frac{\overline{v^{\prime 2}}-\frac{2}{3} e}{e}\right)^{2}\right]
$$

Note that if normal stresses tend to the isotropic value, their contribution vanishes in Eq. 15.

\section{Data and Methods}

\subsection{Experimental Site and Measurements}

The 10-day in situ measurement campaign was conducted from 14 to 23 November 2012 near Grenoble in the French Alps ( $45^{\circ} 9^{\prime} 46^{\prime \prime} \mathrm{N}, 5^{\circ} 54^{\prime} 49^{\prime \prime} \mathrm{E}$, Blein 2016). This period was characterized by anticyclonic conditions that resulted in a strong particle-pollution episode in the valley of Grenoble. A 7-m mast was set up on the west face of Grand Colon in the Belledonne mountain range at an altitude of $1770 \mathrm{~m}$ above sea level (Fig. 2). The surface is covered with sparse small bushes and rocks, whose height is around $0.30 \mathrm{~m}$. Figure 2 shows that the slope is quite homogeneous and of the order of $30^{\circ}$. The spacing between the contour lines suggests a slight decrease of the topographic slope downstream from the mast to the forest $100 \mathrm{~m}$ further.

Four 3D sonic anemometers (CSAT3, Campbell Scientific, Inc. and WindMaster Pro, Gill Instruments, England) were used to measure the three velocity components and sonic temperature profiles at a high sampling frequency of 10-20 Hz (Fig. 2 and Table 2). A 2D sonic anemometer (WindSonic, Gill Instruments), a thermo-hygrometer (CS215, Campbell Scientific), and an infrared thermometer (KT15, Heitronics, Germany) complemented the profile (Table 2).

Blein (2016) classified katabatic events for the whole measurement period in light of the wind direction, mean, and turbulence variables measured at the mast location and of synoptic conditions from ECMWF (European Centre for Medium-Range Weather Forecasts) reanalyses of the area. From that, we selected a case study katabatic event on 19 November 2012, between 1830 and 2100 local time (UTC $+1 \mathrm{~h}$ ). This event complies with the following criteria: (i) External synoptic conditions must be as weak so that the observed flow results only from the katabatic forcing. A threshold maximum wind speed was set to $1 \mathrm{~m} \mathrm{~s}^{-1}$ in 

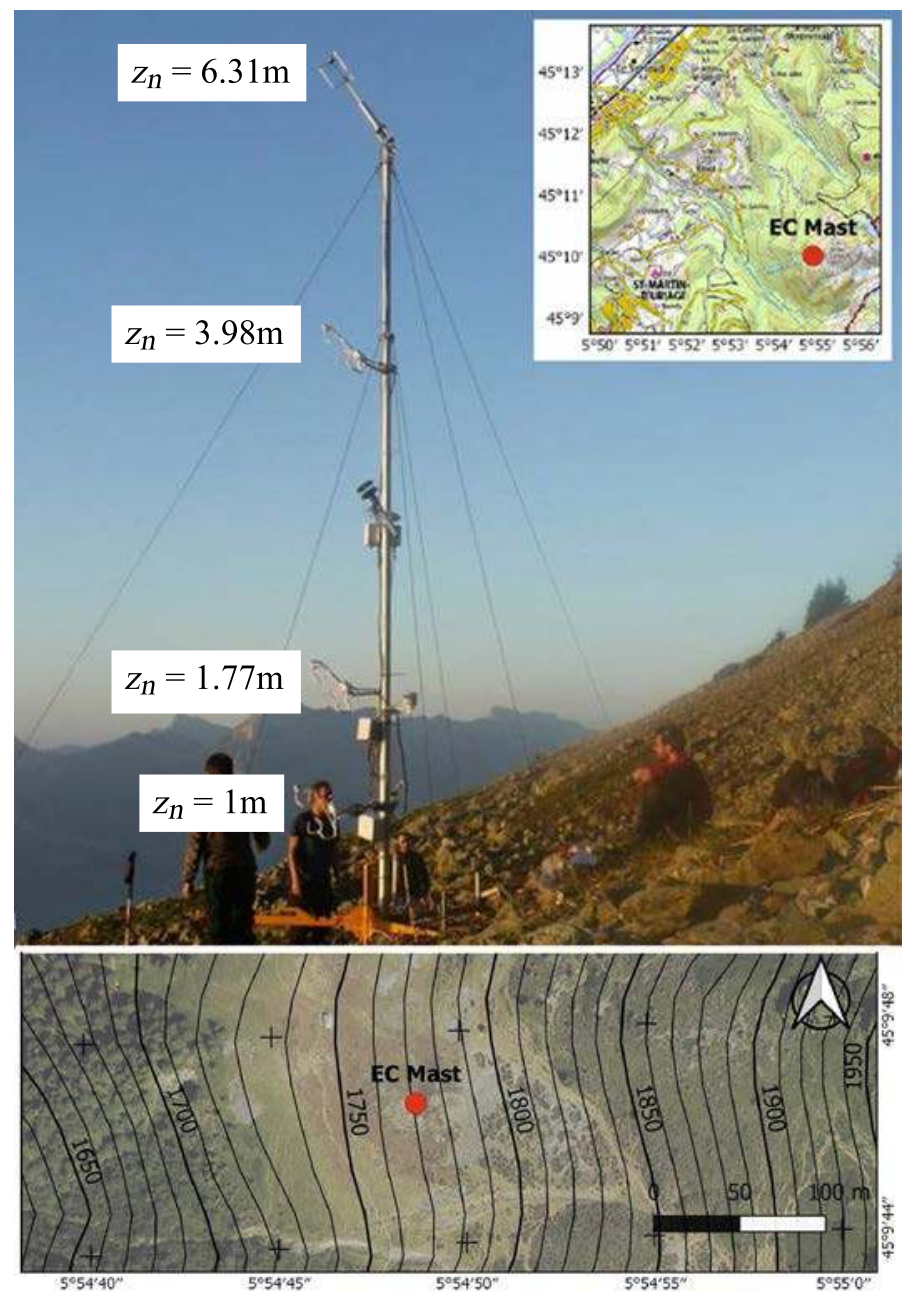

Fig. 2 (Upper panel) Experimental site and mast in Belledonne mountain during the measurement campaign. The four 3D sonic anemometers are labelled with their slope-normal height. (Lower panel) Location of the mast. The slope is directed from east to west. "EC Mast" stands for eddy-eovariance mast

the valley transect (ECMWF reanalyses). (ii) Mean as well as turbulent quantities have to fulfill the steady state assumption during the event, and be validated following the Vickers and Mahrt (1997) quality control. This means that katabatic flow is well established and no external forcing disturbs the analysis of the signal. (iii) We selected a shorter event within the case study event from 1915 to 1945 local time (LT) satisfying the following conditions: transverse fluxes $\overline{v^{\prime} w^{\prime}}, \overline{u^{\prime} v^{\prime}}$ (resp. $\overline{v^{\prime} \theta^{\prime}}$ ) are negligible with respect to $\overline{u^{\prime} w^{\prime}}$ (resp. $\overline{w^{\prime} \theta^{\prime}}$ ) and the spanwise velocity component is as low as possible. This event will be referred to as the pure katabatic event hereafter.

To explore the impact of large-scale forcing, we selected five other periods during the campaign involving more external perturbations and a relatively weaker katabatic forcing. These periods were required to have (i) stationarity in the first and second-order variables (mean, r.m.s., and turbulent fluxes), (ii) a positive vertical gradient of potential temperature 
Table 3 List of katabatic events from the present study. The number of samples is the number of (2-min) segments in each event

\begin{tabular}{llcl}
\hline & Date and local time & Number of samples & Conditions met \\
\hline Case study event & 19 November 1830-2100 & 75 & (i); (ii) \\
Pure event & 19 November 1915-1945 & 15 & (i); (ii); (iii) \\
Disturbed events & 15 November 2000-2200 & 60 & (i); (ii); (iii) \\
& 16 November 0200-0500 & 90 & (i); (ii); (iii) \\
& 16 November 2030-2300 & 75 & (i); (ii); (iii) \\
& 18 November 1800-2030 & 75 & (i); (ii); (iii) \\
& 20 November 0000-0500 & 150 & (i); (ii); (iii) \\
\hline
\end{tabular}

and (iii) a wind speed vertical profile consistent with a jet. These events (hereafter referred to as disturbed episodes), used to extend our analysis, are listed in Table 3.

\subsection{Post-processing of the Dataset}

In a pure katabatic flow configuration (Sect. 2.1), the wind direction is constant and imposed by the topography. The slope-aligned coordinate system that matches the mean flow direction close to the ground is the one recommended for such flow (Oldroyd et al. 2016b). In the present case, we focused only on short periods of a few hours when the katabatic flow was established for which the mean wind direction did not vary significantly over time. The anemometer at $1 \mathrm{~m}$ is placed with an orientation uncertainty of $\pm 1^{\circ}$ with respect to the slope-normal axis (after verification with an inclinometer). The inclination of the streamline at $1 \mathrm{~m}$ was $21^{\circ}$. This is a little different from the topographic slope, probably due to the change of slope observed in Fig. 2 and to downstream conditions (presence of a forest). Thus, for the present study, we choose to define our coordinate system following the streamline at $1 \mathrm{~m}$, with an angle of $\alpha=21 \pm 1^{\circ}$ with respect to the gravity. This choice is often made in katabatic studies (Horst and Doran 1988; Sun 2007; Nadeau et al. 2013b) even if it does not allow focus on entrainment that may exist in a jet. This outstanding issue, which needs to be investigated further, is beyond the scope of the present study. Furthermore, in a pure katabatic flow as defined in Sect. 2.1 as a statistically two-dimensional homogeneous flow, the spanwise velocity component is zero. We thus applied for each measurement level a double rotation to the flow. This consists of nullifying spanwise and slope-normal mean wind speed components over the duration of a given episode that lasts a few hours at most. For example, for the case study episode, we applied a double rotation with a unique pair of rotation angles for the whole sequence 1830-2100 LT.

To calculate the means, variances, and fluxes, we processed the rotated data with EddyPro software developed by Licor based on the eddy-covariance method. We chose the block average method over a sampling period of 2 min determined through an ogive analysis (Moncrieff et al. 2004) for the variances of velocity components, temperature, and for all second-order quantities as well (momentum and sensible heat fluxes). Stiperski and Calaf (2018) computed multi-resolution decomposition (MRD, Howell and Mahrt 1997) on a stable boundary-layer dataset and concluded also that a short time scale (1 min in their case) is the most suitable during stable episodes. This is consistent with the MRD procedure applied by Blein (2016) on the present dataset. Consequently, the pure katabatic event defined in Sect. 3.1 is composed of 15 (2-min) time segments. Frequency corrections applied in EddyPro software 
are built on MOST; therefore we decided not to correct the fluxes to prevent adding MOSTinduced behaviour where this theory is not supposed to apply. Moreover, over complex terrain, Klipp (2018) advise to avoid over-correcting data.

\subsection{Procedure to Determine the Mean Shear from In Situ Measurements}

In the next sections, we focus on the production/consumption of $e$ and $\overline{u^{\prime} w^{\prime}}$ by buoyancy and compare it with the production/consumption of $e$ and $\overline{u^{\prime} w^{\prime}}$ by shear. The latter include the mean flow velocity gradient $\partial_{z_{n}} \bar{u}$ of the katabatic jet in the surface normal direction $z_{n}$ (Eqs. 3, 9). We do not have access to a direct measurement of $\partial_{z_{n}} \bar{u}$ at measurement levels. Instead we design a procedure to rebuild a continuous mean velocity profile $\bar{u}\left(z_{n}\right)$ based on the Prandtl model solution for katabatic jets (e.g., Fedorovich and Shapiro 2009) that fits the in situ measurements. From this analytical profile, we derived the necessary velocity gradient to evaluate the shear terms at all heights where turbulence is measured (Table 2).

Grisogono and Oerlemans (2001) derived an analytical solution for the Prandtl model with a varying eddy viscosity $K_{m}\left(z_{n}\right)$ in the vertical direction. Parmhed et al. (2004) used this solution over a glacier on katabatic events defined as events in which a maximum wind speed exists in the measured profiles. Both studies showed that a varying $K_{m}\left(z_{n}\right)$ is adequate to describe velocity profiles. Based on a recent numerical LES study of a katabatic jet along a steep slope, Brun et al. (2017) modified the Prandtl model to account for $K_{m}\left(z_{n}\right)$ variability as well. They showed that the mean velocity profile is well reproduced when a linear coefficient $K_{m}\left(z_{n}\right) \propto z_{n}$ is used. We apply this result to the Prandtl model length scale and velocity scale in Eqs. 17, 18,

$$
\bar{u}\left(z_{n}\right)=V_{0} \sin \left(\frac{z_{n}}{L_{0}}\right) e^{\left(-z_{n} / L_{0}\right)},
$$

where $V_{0}$ and $L_{0}$ are characteristic velocity and length scales, respectively

$$
\begin{aligned}
& L_{0}=\frac{1}{\operatorname{Pr}^{0.25}} \sqrt{\frac{2 K_{m}^{L_{0}}}{N_{r e f} \sin (\alpha)}} \text { with } K_{m}^{L_{0}}\left(z_{n}\right)=K_{m}^{m i n}+a z_{n} \\
& V_{0}=\operatorname{Pr}^{0.25} \frac{\sqrt{2} g\left|\left(\overline{w^{\prime} \theta^{\prime}}\right)_{s}\right|}{\theta_{s} \sqrt{K_{m}^{V_{0}} N_{\text {ref }}^{3} \sin (\alpha)}}>0 \quad \text { with } K_{m}^{V_{0}}\left(z_{n}\right)=K_{m}^{m i n}+b z_{n}
\end{aligned}
$$

The turbulent Prandtl number may vary along the katabatic jet profile (e.g., Stiperski et al. 2020), especially in the region of the jet maximum height where turbulent momentum flux vanishes leading to sharp $\operatorname{Pr}$ variations from 0 to $\infty$. In the region above/below the jet maximum $\mathrm{Pr}$ is better defined. In this study an estimation above the jet maximum height for the pure katabatic event provides a Prandtl number of about $\operatorname{Pr}=2$. Note that $\operatorname{Pr}^{1 / 4}$ matters in the fitting Prandtl model, so that a variation in $P r$ is damped: $P r=2$ leads to $\operatorname{Pr}^{1 / 4}=1.19$, which is close to 1 . As an average value for the fitting Prandtl model, we finally set $P r=1$ in the present model to fit magnitudes generally used in the literature (Parmhed et al. 2004). Ambient stratification $N_{\text {ref }}$ is set to $0.02 \mathrm{~Hz}$. The surface kinematic sensible heat flux, $\left(\overline{w^{\prime} \theta^{\prime}}\right)_{s}=H_{s} /\left(\rho C_{p}\right)$, with $H_{s}=-50 \mathrm{~W} \mathrm{~m}^{-2}$, is extrapolated from the turbulent heatflux profiles close to the surface (Table 1; Blein 2016; Brun et al. 2017) where $\rho$ is the density and $C_{p}$ is the heat capacity of the air. Surface temperature $\theta_{s}=270 \mathrm{~K}$ is estimated from the KT15 radiation sensor. Three coefficients are set to fit the results from the present data in the pure katabatic event: $a=0.015 \mathrm{~m} \mathrm{~s}^{-1}, b=0.0098 \mathrm{~m} \mathrm{~s}^{-1}$, and $K_{m}^{\text {min }}=0.0092 \mathrm{~m}^{2} \mathrm{~s}^{-1}$. We 
use this procedure to estimate the position of the maximum wind speed $z_{j}$ and the sign as well as the magnitude of the wind speed gradient $\partial_{z_{n}} \bar{u}$.

\section{Results and Discussion}

\subsection{Pure Katabatic Episode Versus Case-Study Katabatic Episode}

Figure 3 shows the temporal evolution of TKE $e$ during the evening of November 19th, from 1700 to $2200 \mathrm{LT}$ at $1 \mathrm{~m}$ and $3.98 \mathrm{~m}$. We restrain the study to the case where TKE is stationary between 1830 and 2100 LT, which is the case-study katabatic event (Sect. 3.1). Figure 3 also presents the mean streamwise velocity component $\bar{u}$ and temperature $\bar{T}$, as well as the spanwise velocity $\bar{v}$ and the spanwise residual turbulent shear stress $\overline{u^{\prime} v^{\prime}}$ during this case-study event. We observe some oscillations in the mean streamwise and spanwise velocity time series, along with some spikes and non-negligible values of $\overline{u^{\prime} v^{\prime}}$. McNider (1982) explains that oscillations in drainage flows may occur at a period $\tau=2 \pi\left[\sin (\alpha) N_{\text {ref }}\right]^{-1}$, which is approximately $15 \mathrm{~min}$. This order of magnitude is consistent with the present data. The heterogeneity in the behaviour of $\bar{u}, \bar{v}$ and $\overline{u^{\prime} v^{\prime}}$ stipulates us to extract a shorter period with better statistical properties between 1915 and 1945 LT. This is the pure katabatic event described in Sect. 3.1. As expected in anticyclonic conditions, the vertical temperature gradient from the ground surface and along the whole mast profile is positive during the night, and is around $4 \mathrm{~K} \mathrm{~m}^{-1}$ within the first metre. During the case-study episode, relative humidity was close to $40 \%$, corresponding to a very low specific humidity of about $2.3 \mathrm{~g} \mathrm{~kg}^{-1}$. This corresponds to a deviation of sonic temperature from temperature of $0.14 \%$, and from virtual temperature of $0.02 \%$. Sonic temperature is thus used instead of temperature or virtual temperature throughout this study (Kaimal and Finnigan 1994).

Unless otherwise specified, the following analysis and the next figures are presented for the pure katabatic event (1915-1945 LT).

\subsection{Wind Speed and Turbulent Quantities for the Pure Katabatic Event}

Figure $4 \mathrm{a}$ presents the pure katabatic wind-speed profile. The maximum wind speed is estimated to be at $z_{j} \approx 1.36 \mathrm{~m}$ based on the Prandtl model analysis (Sect. 3.3), which provides a perfect fit with the measurements. This height is in agreement with the analysis performed by other authors over steep slopes (Table 1). Figure $4 \mathrm{~b}$ shows the main turbulent shear stress $\overline{u^{\prime} w^{\prime}}$ at the four levels of measurement (black dots). It is of opposite sign with respect to $\partial_{z_{n}} \bar{u}$ for most of the levels along the profile, as expected from the classic theory of shear flows. According to Grachev et al. (2016), the change of sign of $\overline{u^{\prime} w^{\prime}}$ is the best method for the determination of $z_{j}$, along with the change of sign of $\overline{u^{\prime} \theta^{\prime}}$, but this is based on the assumption that the positions of the maximum wind speed $z_{j}$ and of the change of sign of $\overline{u^{\prime} w^{\prime}}$ are at exactly the same height. This was not the case in the present measurements, and we do not expect the Boussinesq hypothesis (Eq. 4) to be valid in the region near the maximum wind speed where mean shear weakens and vanishes. In addition, such counter-gradient fluxes around the maximum of wind speed have already been observed for experiments of wall jets (e.g., Irwin 1973; Eriksson et al. 1998; Krug et al. 2013) and in DNS or LES of katabatic jets along a steep slope (e.g., Fedorovich and Shapiro 2009; Giometto et al. 2017; Brun et al. 2017), although none of them agree on the region-above versus below the maximum jet height—where it appears. 

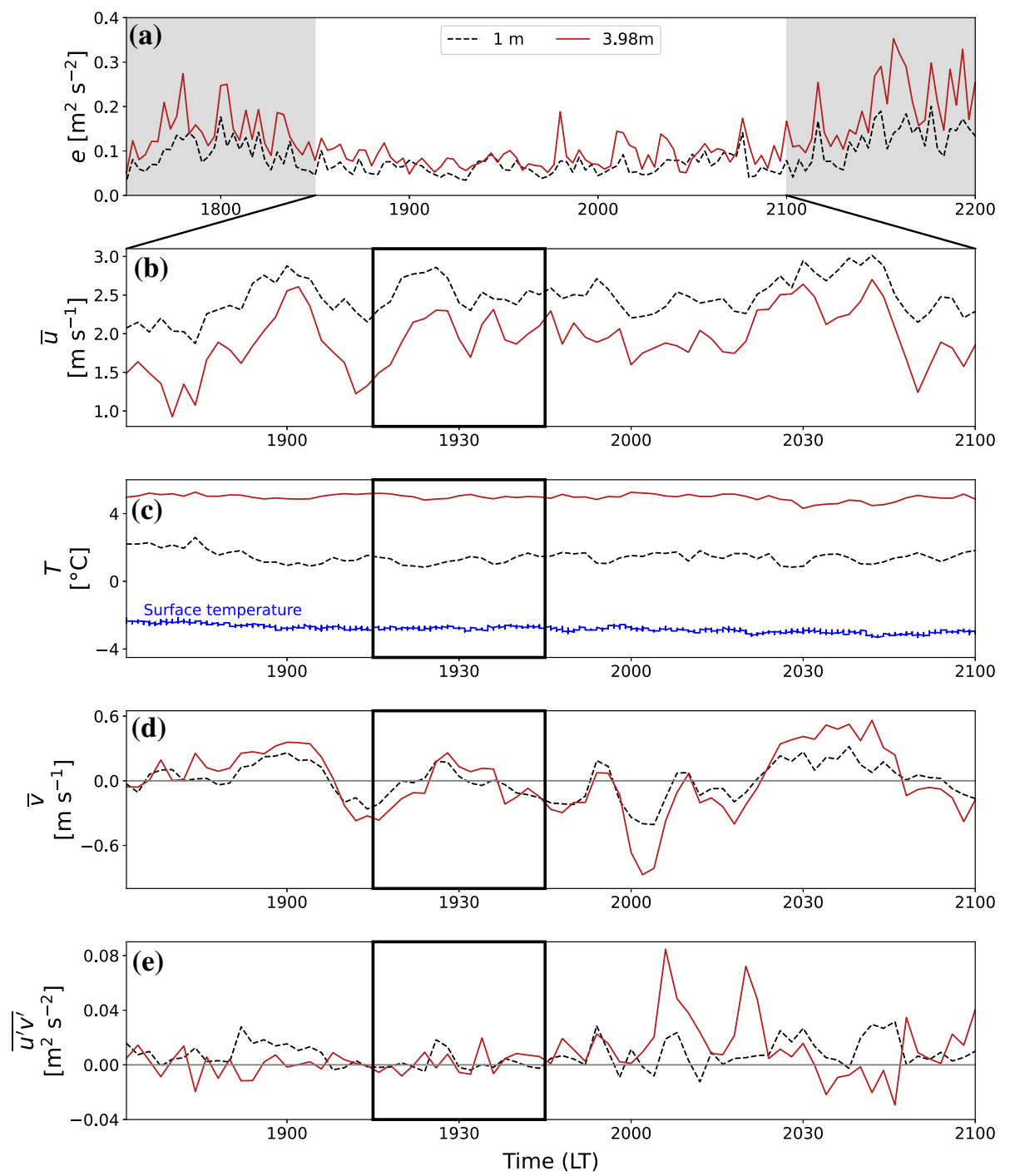

Fig. 3 Turbulence kinetic energy (a), streamwise velocity (b), temperature and surface temperature (c), spanwise velocity (d) and turbulent shear stress $\overline{u^{\prime} v^{\prime}}$ (e) in the slope-following coordinate system for the measurement levels at $1 \mathrm{~m}$ and $3.98 \mathrm{~m}$. White area in a shows the case study katabatic episode. The black boxes highlight the pure katabatic episode

We consequently separate the katabatic surface layer into three regions (Fig. 4):

- The inner layer region: up to $z_{j}=z_{n}\left(\partial_{z_{n}} \bar{u}=0\right)$, which corresponds to $1.36 \mathrm{~m}$ in our case.

- The region around the maximum wind speed, between $z_{j}$ and the change of sign of the turbulent momentum flux $z_{m}$ : from $z_{j}=1.36 \mathrm{~m}$ to $z_{m}=2.83 \mathrm{~m}$ in our case. Note that we linearly link measurement levels for better readability of the profiles (Fig. 4), but it is likely that the height at which $\overline{u^{\prime} w^{\prime}}$ cancels is smaller. 

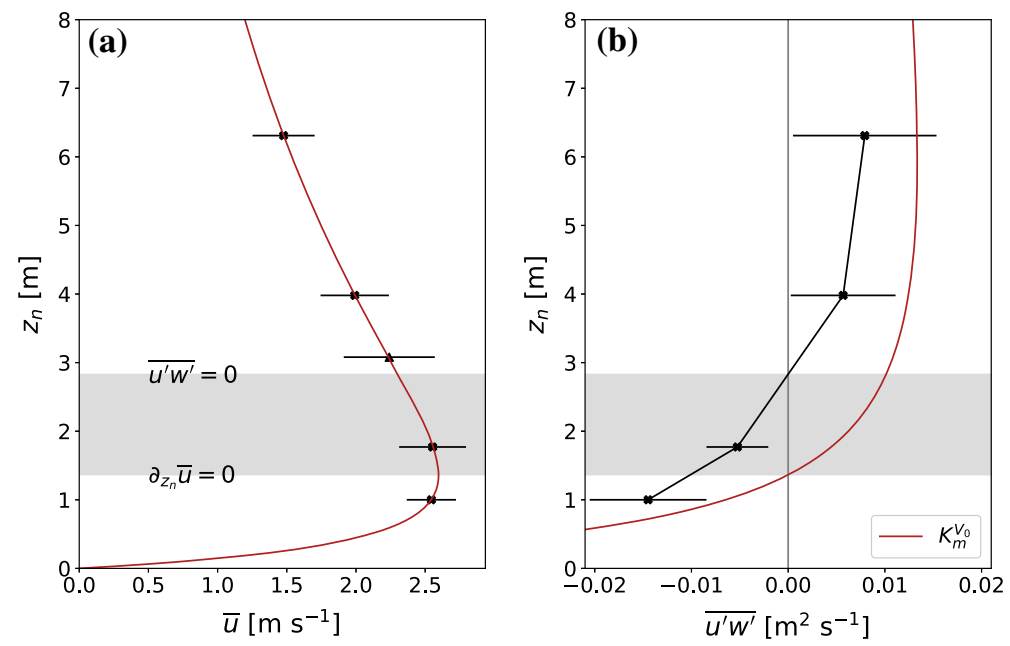

Fig. 4 a Slope-normal profile of wind speed and $\mathbf{b}$ of the turbulent shear stress in the direction of flow. The dot (resp. the error bars) represent the median (resp. the standard deviation) of the 15 (2-min) segments in the pure katabatic episode (from 1915 to 1945 LT on 19 November 2012). The red curves shows results from the fitting procedure. In the right panel, the momentum flux is fitted with the $K_{m}^{V_{0}}$ parameter. The grey areas represent the transition region near the maximum wind-speed height. In this region we expect the Boussinesq hypothesis (Eq. 4) to fail, which means that turbulent momentum flux is poorly linked with the mean velocity gradient

- The outer layer shear region of the jet: above $z_{m}$ which corresponds to $2.83 \mathrm{~m}$ for the present study.

The region around the maximum wind speed is shown in grey, with an approximate thickness due to the uncertainty of the two positions $z_{j}=z_{n}\left(\partial_{z_{n}} \bar{u}=0\right)$ and $z_{m}=z_{n}\left(\overline{u^{\prime} w^{\prime}}=0\right)$. Figure $4 \mathrm{~b}$ also shows the turbulent shear stress determined from the Prandtl fit (Eqs. 4, 16). The Prandtl fit globally predicts momentum fluxes of the same order of magnitude as the measured momentum fluxes and provides a fair validation of the present fit procedure. However, the momentum flux changes sign exactly at the position of the maximum wind speed due to the non-validity of Eq. 4 in the region around the maximum wind speed.

Figure 5 presents profiles of all of the turbulent sensible heat fluxes, and the two spanwise turbulent shear stresses as well as the TKE and the three wind velocity variances. We first focus on the turbulent sensible heat flux, statistically averaged over the pure katabatic episode of $30 \mathrm{~min}$, which is decomposed into a slope-normal component $\overline{w^{\prime} \theta^{\prime}}$, a streamwise component $\overline{u^{\prime} \theta^{\prime}}$, and a residual spanwise component $\overline{v^{\prime} \theta^{\prime}}$. In agreement with theory (Sect. 2), $\overline{w^{\prime} \theta^{\prime}}$ is always negative and decreases in magnitude with height along the profile. $\overline{u^{\prime} \theta^{\prime}}$ is negative in the outer layer of the jet and positive below the region of $z_{j}$. The change in the sign of $\overline{u^{\prime} \theta^{\prime}}$ occurs near the height of the maximum wind speed determined using the Prandtl method. Note that $\overline{u^{\prime} \theta^{\prime}}$ is higher in magnitude than $\overline{w^{\prime} \theta^{\prime}}$, as $\left|\overline{u^{\prime} \theta^{\prime}}\right|$ reaches a magnitude of $0.05 \mathrm{~K} \mathrm{~m} \mathrm{~s}^{-1}$ while maximum value of $\left|\overline{w^{\prime} \theta^{\prime}}\right|$ is around $0.03 \mathrm{~K} \mathrm{~m} \mathrm{~s}^{-1}$. The spanwise sensible heat flux $\overline{v^{\prime} \theta^{\prime}}$ is close to zero along the profile, with a slight contribution close to the surface, possibly due to the increase of the temperature variance and the strong mean temperature gradient in this region.

The two spanwise turbulent shear stresses $\overline{u^{\prime} v^{\prime}}$ and $\overline{v^{\prime} w^{\prime}}$ are very small compared to $\overline{u^{\prime} w^{\prime}}$ (Fig. 4). The magnitude of $\overline{u^{\prime} v^{\prime}}$ is a little higher at the upper level, which is consistent with 

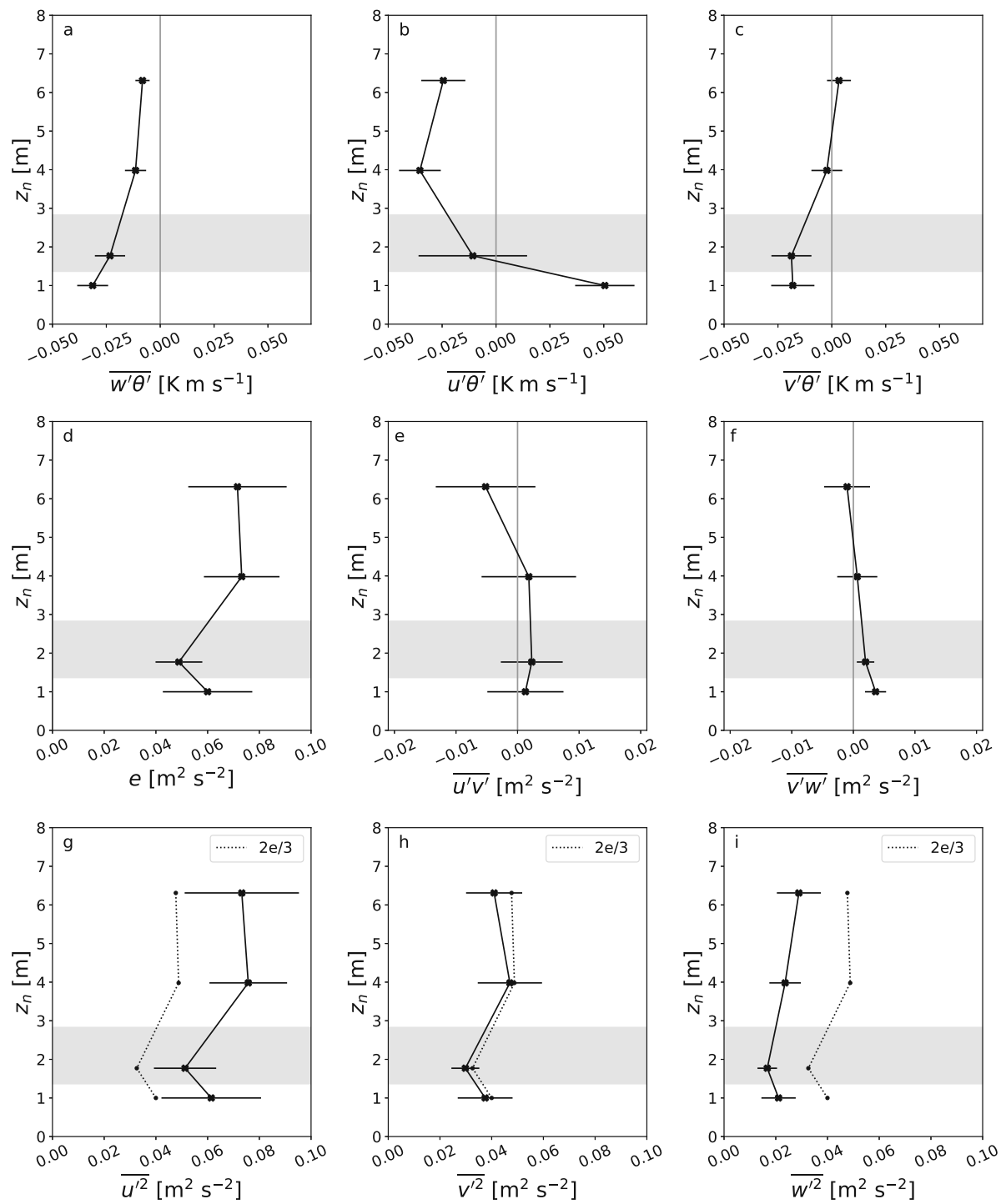

Fig. 5 (First line) Slope-normal profiles of the turbulent sensible heat flux: a slope-normal component, b along-slope component, c spanwise component. (Second line) Slope-normal profile of TKE (d) and turbulent shear stresses with a spanwise component $(\mathbf{e}, \mathbf{f})$. (Third line) Slope-normal profiles of velocity variances: (g) along-slope, (h) spanwise, and (i) slope-normal. On (g-i), the dotted line is $2 \mathrm{e} / 3$ of TKE, which is the isotropic value for velocity variances. The dot (resp. the error bars) represent the median (resp. the standard deviation) of the 15 (2-min) segments in the pure katabatic episode (from 1915 to 1945 LT on 19 November 2012). The grey areas represent the transition region near the maximum wind-speed height

the interaction of the jet with external conditions. Turbulence kinetic energy (Fig. 5d) shows the same order of magnitude below and above the maximum velocity region with a local minimum that seems to appear in the region of the maximum wind speed, where shear is at its minimum and vanishes (Grachev et al. 2016; Brun et al. 2017). This is consistent with the development of two mixing regions, one above and one below the Level of maximum 
wind-speed. Turbulence level, defined as $\sqrt{e} / \bar{u}_{\text {max }}$, ranges from 8.5 to $10.5 \%$ along the mast, and corresponds to a fully turbulent state of the flow (>5\%, Pope 2000).

\subsection{Turbulence Anisotropy}

From Fig. 5g-i, we observe that the TKE is not isotropic, following the hierarchy $\overline{u^{\prime 2}}>\overline{v^{\prime 2}}>$ $\overline{w^{\prime 2}}$, which is classical in a simple turbulent shear flow with statistically two-dimensional homogeneous conditions in the spanwise direction, such as a neutral turbulent boundary layer or turbulent plane jet (Pope 2000). We presently get $\overline{u^{\prime 2}} \approx 50 \%$ larger than $\overline{v^{\prime 2}}$ and three times $\overline{w^{\prime 2}}$ values at all elevations. This trend is observed for all katabatic jets in the literature (Giometto et al. 2017; Brun 2017) but specific features are found in the present case. Note that the streamwise velocity variance is quite close to the TKE, which is consistent with the fact that the only significant mechanical production term (Eq. 3) in the TKE budget (Eq. 1) is the dominant source term as in the $\overline{u^{\prime 2}}$ budget (Pope 2000). Also note that the spanwise velocity variance $\overline{v^{\prime 2}}$ is quite close to the isotropic value of the TKE. Again, this is consistent with the fact that there is no mechanical production in the spanwise direction so that $\overline{v^{\prime 2}}$ may return faster to isotropy conditions, due to the pressure redistribution terms from the largest normal stress to the smaller normal stresses (Pope 2000). In the present study, we analyze the effects of buoyancy production (Eq. 2) on the TKE budget. $P_{B}^{e}$ can be split into two terms, which each play as source or sink term for the $\overline{w^{\prime 2}}$ budget and the $\overline{u^{\prime 2}}$ budget and modify the final anisotropy of the flow.

Figure 6 shows the contribution of each term of the Reynolds stress tensor to the anisotropy coefficient $F$ (Eq. 14) through the second invariant $I_{2}$ for the four measurement levels. For all levels, variances $\overline{u^{\prime 2}}$ and $\overline{w^{\prime 2}}$ contribute the most to $F$, proportionally to their deviation from the isotropic value of $2 e / 3$ (see Fig. 5). The contribution of $\overline{v^{\prime 2}}$ is almost zero (Fig. 5h). As expected for the pure katabatic event, the contribution of the spanwise shear stresses $\overline{u^{\prime} v^{\prime}}$ and $\overline{v^{\prime} w^{\prime}}$ is negligible with respect to the contribution of the main shear stress $\overline{u^{\prime} w^{\prime}}$. The latter is the most important in the inner region of the jet $(1 \mathrm{~m})$ where the mean shear is large, and its magnitude can be as much as the magnitude of variances contribution to $F$. For the other levels, the relative contribution of $\overline{u^{\prime} w^{\prime}}$ is less important but still significant. At the upper measurement level $(6.31 \mathrm{~m})$, we observe an increasing contribution of $\overline{u^{\prime} v^{\prime}}$ that is still smaller than $\overline{u^{\prime} w^{\prime}}$. The contribution of the spanwise variance $\overline{v^{\prime 2}}$ also appears at the last level. These are probably due to the presence of a light transverse wind in the layer above the jet (see Sect. 4.2 and Fig. 5).

Figure 7 shows the anisotropy coefficient $F$ in its complete form (Eq. 14). We compare the independent contribution of each component separately, and confirm the predominance of $\overline{u^{\prime 2}}$ and $\overline{w^{\prime 2}}$ at all levels and the emergence of $\overline{u^{\prime} w^{\prime}}$ at $1 \mathrm{~m}$ in the anisotropy coefficient $F$. Each of these 3 components contributes down to about $0.8<F<0.9$ separately. Other components are marginal in the final determination of $F$ as expected for this pure katabatic event, so that Eq. 15 is a fair approximation for $F$, with even the cancellation of the spanwise contribution of $\overline{v^{\prime 2}}$ for the present data (Fig. 7; red dashed line versus red solid line). Note that the 4 measurement levels are distributed from part to part of the jet maximum height and do not cover the region very close to the ground surface, compared to what is available when performing a DNS of a katabatic jet (e.g., Giometto et al. 2017), and therefore conclusions may differ concerning the behaviour of $F$ in the full katabatic layer. In the present pure katabatic event, a decrease of $F$ is observed from the outer layer region to the inner layer, in 

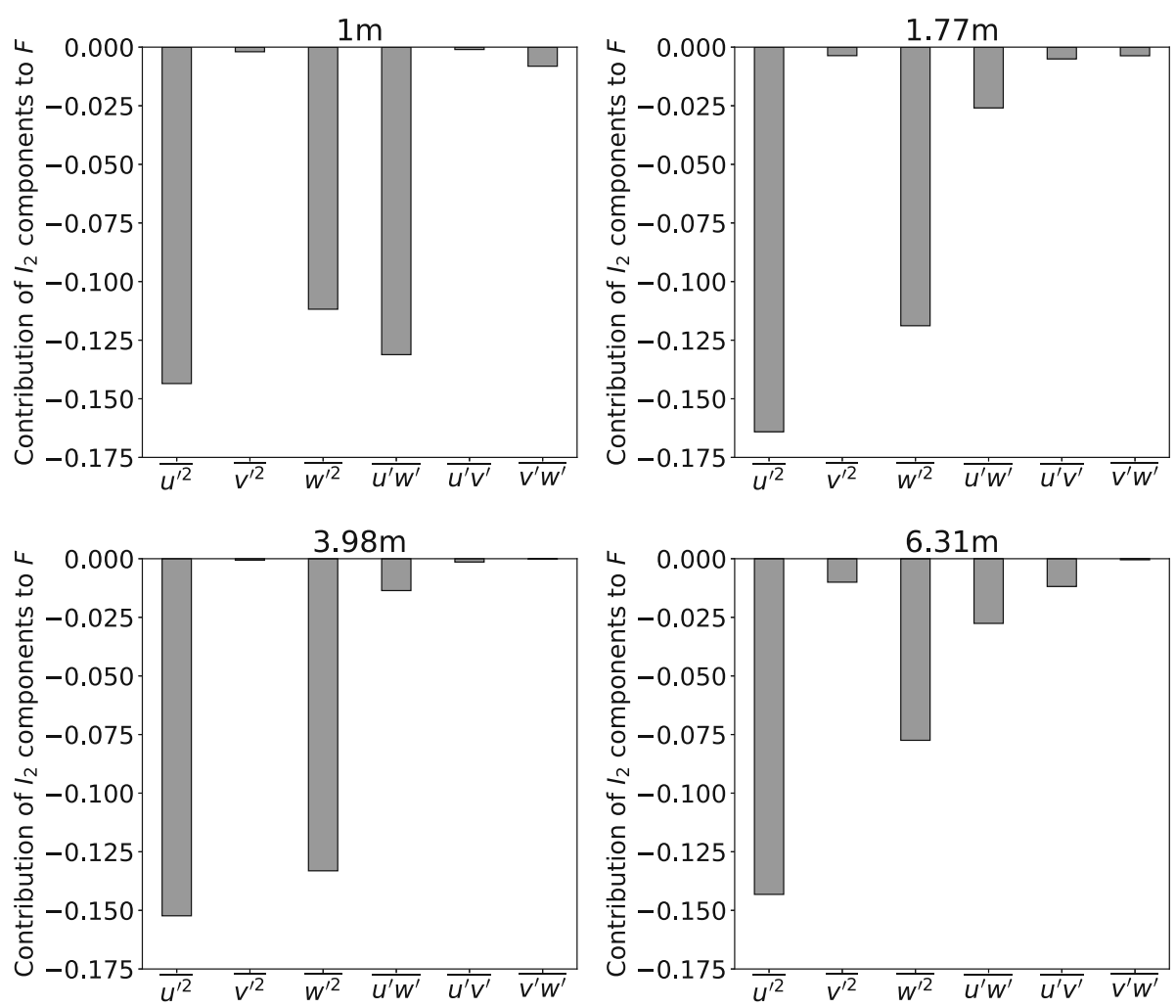

Fig. 6 Contribution of components of the Reynolds stress tensor (normal and shear stresses) to $F$ via the components of $I_{2}$ for the four measurement levels during the pure katabatic episode

the range $0.62<F<0.77$, which is consistent with the anisotropy level obtained with LES in a similar case (Brun 2017).

We also validate the assumption that the contribution of $I_{3}$ to $F$ is really small with respect to $I_{2}$ (red dotted line versus red solid line in Fig. 7). Finally, we compare the case study of a katabatic episode (Fig. 7 blue lines) with the pure katabatic episode (Fig. 7 red lines) and show that the spanwise contribution of $\overline{u^{\prime} v^{\prime}}$ and $\overline{v^{\prime} w^{\prime}}$ is still marginal for both cases. The same conclusions are drawn in terms of vertical trend with a slightly larger anisotropy for the case study episode with a coefficient in the range $0.55<F<0.75$.

\subsection{Buoyancy Terms as a Source or Sink}

In this section, we determine how the buoyancy terms of the TKE and Reynolds shear stress budget equations (Eqs. 2, 8) modify $e$ and $\left|\overline{u^{\prime} w^{\prime}}\right|$ respectively. Figure 8 shows the two terms $P_{B}^{e}$ and $P_{B}^{s}$ as a function of their relative slope-normal position in the jet (in red). We first focus on the pure katabatic episode symbolized by the boxplots. In the inner-layer part of the jet, buoyancy tends to destroy TKE $e$ as well as turbulent momentum flux $\overline{u^{\prime} w^{\prime}}$ as expected in a stable boundary layer. Above the region of the maximum of wind speed, buoyancy slightly increases $e$ and decreases $\left|\overline{u^{\prime} w^{\prime}}\right|$, decreasing $\left(\overline{u^{\prime} w^{\prime}} / e\right)^{2}$. This consequently brings turbulence closer to isotropy (Eq. 15). In the region around the maximum wind speed, buoyancy destroys 


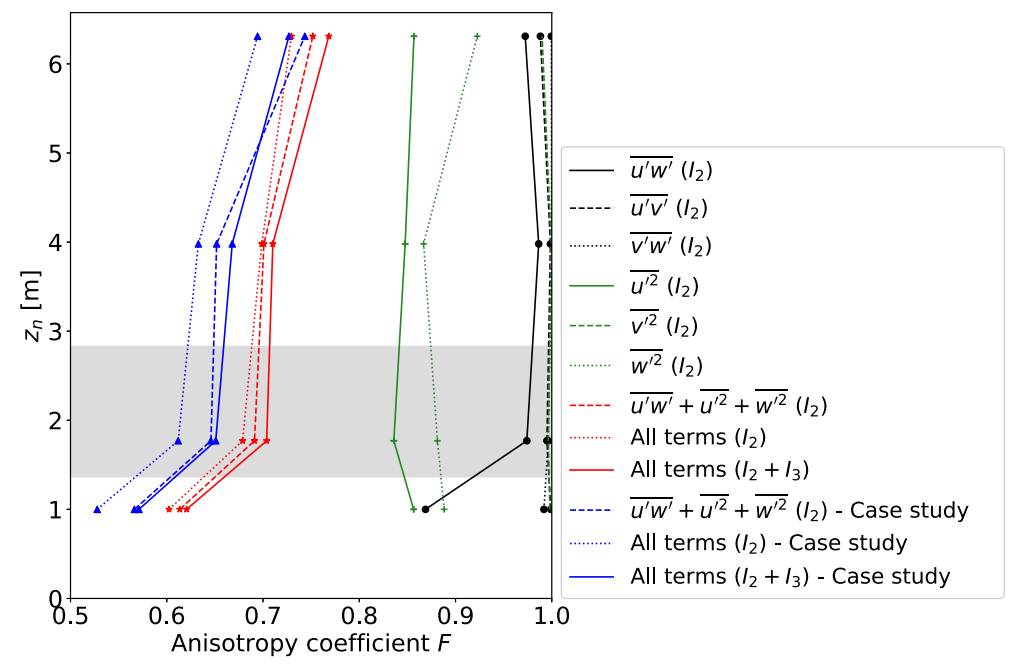

Fig. 7 Anisotropy coefficient $F$ for the pure episode from 1915 to 1945 LT. In black is $F$ with only the contribution of the turbulent shear stresses, in green with only the variances. In red, $F$ is calculated with the three main contributions, with all the terms from the second invariants and with all the terms that compose it. For comparison, we added the equivalent of the red curves for the case study event in blue. Except for the curves named "All terms", we only looked at the contribution of $I_{2}$ to $F$, which is $-\frac{9}{2} a_{i j} a_{j i}$, with fixed $i$ and $j$

TKE. It is the only region where buoyancy may produce $\left|\overline{u^{\prime} w^{\prime}}\right|$. Considering the term $\left(\frac{\overline{u^{\prime} w^{\prime}}}{e}\right)^{2}$ in Eq. 15, buoyancy brings more anisotropy to the flow close to the maximum wind speed. The coefficient of anisotropy $F$ ranges from 0.62 to 0.77 increasing with height along $z_{n}$, meaning more anisotropy close to the surface. This is consistent with the presence of the surface (Giometto et al. 2017), with the effect of buoyancy on turbulence anisotropy in the katabatic jet and in agreement with the numerical results obtained by Brun (2017).

Statistics for all five events described in Table 3 along with the case study katabatic episode are also presented in Fig. 8 (red diamonds). The mean behaviour of the TKE buoyancy term is particularly robust. The spread of $P_{B}^{e}$ is greatest below and in the region of the maximum wind speed. This might be due to the variability of surface cooling during the measurement campaign. Buoyancy production is very close to zero in the outer-layer region of the jet, while $P_{B}^{S}$ displays almost the same behaviour during the pure katabatic episode as that observed during all the other events.

\subsection{Impact of Slope on the Buoyancy Term}

Figure 8a also shows the slope-normal term $\frac{g}{\bar{\theta}} \overline{w^{\prime} \theta^{\prime}}$ in order to highlight the effect of the slope on $P_{B}^{e}$. In the pure katabatic episode (blue boxplots) and in the inner-layer region of the jet, the consumption of TKE is enhanced by a positive along-slope sensible heat flux $\overline{u^{\prime} \theta^{\prime}}$. In the outer-layer region, the along-slope heat flux causes the buoyancy term $P_{B}^{e}$ to change sign compared to a situation in which only the slope-normal component of the turbulent sensible heat flux $\overline{w^{\prime} \theta^{\prime}}$ is considered. In the region around $z_{j}$, the same trend is observed but the median of $P_{B}^{e}$ is still negative. Even in the presence of external forcing observable in the disturbed events (blue stars), buoyancy can play a role in the production of TKE above the jet. The 

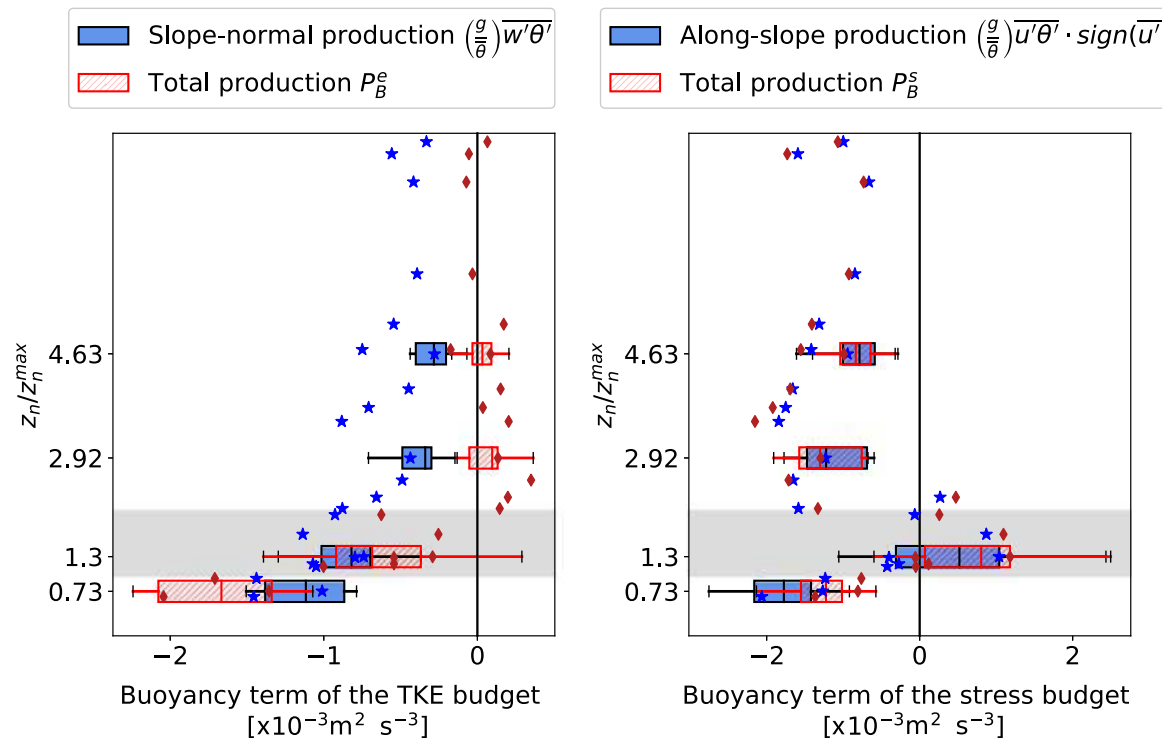

Fig. 8 a Buoyancy production / consumption of TKE $P_{B}^{e}$ calculated from the vertical heat flux (Eq. 2, red diamonds and boxplots) and calculated as if the whole contribution of buoyancy were along the slope-normal axis (blue stars and boxplots at the 4 turbulent levels listed in Table 2. b Buoyancy production / consumption of the turbulent momentum flux $P_{B}^{S}$ calculated from the horizontal heat flux (Eq. 8, red) and as if the whole contribution of buoyancy were along the slope (blue). The boxplots represent the pure katabatic episode (1915-1945 LT). The rectangle in the boxplots represent the interquartile range, the vertical bar inside it is the median of the data. The dots represents the median values for the case study katabatic episode along with the five disturbed episodes defined in Table 3. Note that the vertical axis is normalized by the jet maximum height, which varies between the episodes

transition from consumption to production of TKE is not systematic (see boxplots and some diamonds in Fig. 8), because the magnitude of $\overline{u^{\prime} \theta^{\prime}}$ in the outer layer of the jet is not sufficient in some of the events to cause $P_{B}^{e}$ to be positive. However, the general influence of the slope on $P_{B}^{e}$ in this region is relatively constant, with at least a reduction of the consumption of TKE by buoyancy if not production.

To our knowledge, only Horst and Doran (1988) and Oldroyd et al. (2016a) clearly demonstrated experimentally a positive $P_{B}^{e}$ term in katabatic winds in stable conditions for steep slopes (resp. $\alpha=21$ and $35.5^{\circ}$ ). This behaviour has also been observed in DNS studies, as in Giometto et al. (2017). Figure 9, adapted from Oldroyd et al. (2016a), shows the ratio between along-slope and slope-normal turbulent sensible heat fluxes, as a function of the slope $\alpha$ in several studies of katabatic winds (Table 1). Data over gentle slopes were collected by Grachev et al. (2016): the ratio of sensible-heat-flux components did not exceed the threshold given in Eq. 5, except in some cases in which this critical value was approached. For an angle of $21^{\circ}$, which corresponds to a similar local angle in the present study, Horst and Doran (1988) showed that production of TKE can occur in the external part of the katabatic jet but their analysis was limited to only one level of measurement. Over a steeper slope, Oldroyd et al. (2016a) showed that the buoyancy term was clearly positive above the maximum wind-speed height in katabatic flows in most of the 495 (10-min) segments they studied. However, this behaviour is only observed during katabatic events: for the boundarylayer cases without a jet shape (237 (10-min) segments observed by Oldroyd et al. 2016a), buoyancy acts as a TKE sink. We added our observations in the case of the pure katabatic 


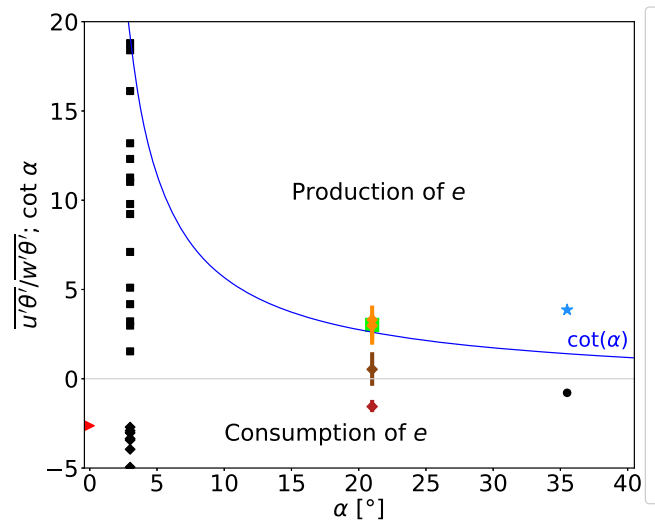

Horst and Doran (1988), above jet peak. $\mathrm{N}_{P}=1$

Grachev et al. (2016),

- above jet peak. $\mathrm{N}_{P, i}=1$

Grachev et al. (2016),

- below jet peak. $\mathrm{N}_{P, i}=1$

Wyngaard et al. (1971),

flat terrain. $\mathrm{N}_{P}=27$

Oldroyd et al. (2016),

above jet peak. $\mathrm{N}_{P}=495$

Oldroyd et al. (2016),

- downslope wind. $\mathrm{N}_{P}=237$

- This study, above jet peak. $\mathrm{N}_{P}=15$

This study, in the region of the

- maximum wind speed jet peak. $\mathrm{N}_{P}=15$

- This study, below jet peak. $\mathrm{N}_{P}=15$

Fig. 9 Inspired by Oldroyd et al. (2016a), representation of Eq. 5. The blue line represents the limit, above which TKE is produced by buoyancy effects. $N_{P}$ is the number of segments used for the computation of the ratio of sensible heat fluxes. The diamonds from this study represent the median of the pure episode, and the vertical bar is the interquartile range. Downslope winds are winds with no maximum wind speed in their profile. The relative position of the measurement point with respect to the jet peak is indicated in the legend
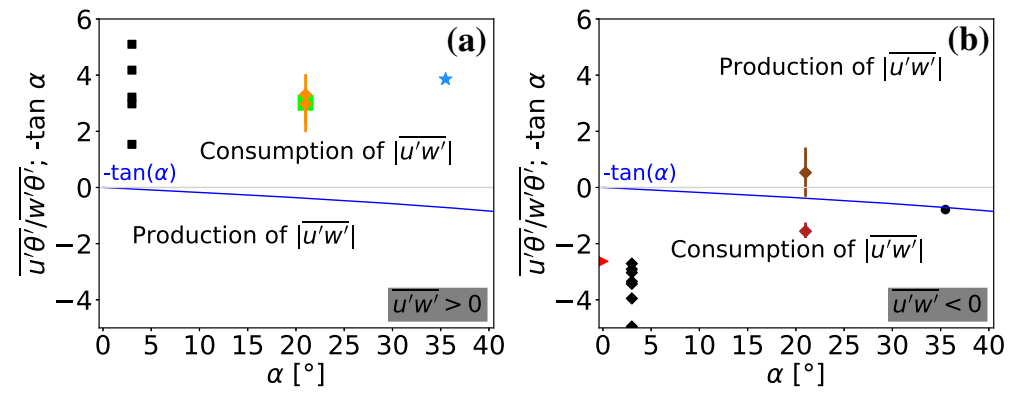

Fig. 10 Same legend as in Fig. 9. a Representation of Eq. 12a and b representation of Eq. 12b The blue line represents the limit separating production and consumption of $\left|\overline{u^{\prime} w^{\prime}}\right|$ by buoyancy effects

event to complete the lack of turbulent measurements over steep slopes. Our dataset has the advantage of containing turbulence measurement data at four levels below, within, and above the region of $z_{j}$. The ratio $\overline{u^{\prime} \theta^{\prime}} / \overline{w^{\prime} \theta^{\prime}}$ exceeds the threshold value of $\cot (\alpha)=2.6$ in the upper part of the profile above a height of $3 \mathrm{~m}$ but not in the region below or around the maximum wind-speed height. This confirms the results of Oldroyd et al. (2016a) showing that buoyancy contributes to TKE production if the along-slope heat flux is large enough, but Oldroyd et al. (2016a) did not show measurements taken in the inner layer of the katabatic jet.

The same approach is now applied for the buoyancy production term of the stress budget (Fig. 8b). In the definition of $P_{B}^{s}$ (Eq. 8), the large magnitude of $\overline{u^{\prime} \theta^{\prime}}$ (Figs. 3, 5) is combined with $\sin \alpha$ while $\overline{w^{\prime} \theta^{\prime}}$ is combined with $\cos \alpha$. This causes the effect of slope on the behaviour of $P_{B}^{s}$ to be negligible compared to $P_{B}^{e}$ (Fig. 8). The buoyancy term $P_{B}^{s}$ is thus mainly driven by the along-slope sensible heat flux $\overline{u^{\prime} \theta^{\prime}}$ in the stress budget equation. These conclusions concerning $P_{B}^{S}$ behaviour are exactly the same for the pure katabatic episode and for the ensemble composed by the events presented in Table 3 .

Figure 10 shows the ratio between along-slope and slope-normal turbulent sensible heat fluxes as a function of the slope angle $\alpha$. This makes it possible to visualize condition 
expressed in Eq. 12a, b with $-\tan (\alpha)$, the limit between production and consumption of $\left|\overline{u^{\prime} w^{\prime}}\right|$. For all data above the level of maximum wind speed, buoyancy tends to consume the momentum flux for gentle slopes as well as for steep slopes (Fig. 10a). For data below jet peak, buoyancy also consumes $\left|\overline{u^{\prime} w^{\prime}}\right|$ (Fig. 10a). Turbulence mixing is enhanced by the momentum flux through the mixing coefficient (Eq. 4). This means that turbulent mixing on both sides of the jet peak decreases due to buoyancy. For the only point of measurement we have in the region of the maximum wind speed $\left(z_{n}=1.77 \mathrm{~m}\right)$, production of momentum flux occurs, as expected from Fig. 8. Note that consumption of $\left|\overline{u^{\prime} w^{\prime}}\right|$ is also observable over a flat terrain (Wyngaard et al. 1971). For downslope winds without a jet shape, there is no clear behaviour of the buoyancy term with respect to $\left|\overline{u^{\prime} w^{\prime}}\right|$ : neither production nor consumption is clearly observable. These data are placed over the neutral limit represented by $-\tan (\alpha)$ (Fig. 10b).

\subsection{Stability Effects Related to Richardson Numbers}

The effect of buoyancy on TKE and on $\left|\overline{u^{\prime} w^{\prime}}\right|$ is compared to the shear effects, which can be quantified with the mechanical production terms $P_{M}^{e}$ and $P_{M}^{s}$ respectively. This section discusses possible parameters to determine the combined effects of shear and buoyancy.

\subsubsection{Turbulent Flux Richardson Number}

Figure 11 shows the flux Richardson number $R_{f}$ for the pure katabatic episode at the four measurement levels. The inner-layer region of the jet behaves like a classical turbulent boundary layer, with $P_{M}^{e}>0$. At the only point of measurement we have in this region $\left(z_{n}=1 \mathrm{~m}\right)$, buoyancy destroys TKE; $R_{f}$ is thus positive, meaning a statically stable state. In the outerlayer shear region of the jet, the mean shear acts in the same way as in the inner-layer region with $P_{M}^{e}>0$, which makes it possible to use $R_{f}$ sign as an indicator of the stability of the flow: $R_{f}$ is slightly negative but close to neutrality. Both shear and buoyancy generate turbulence in this case, but the buoyancy effect is weak so $R_{f}$ remains close to zero.

The region of maximum wind speed is the region where $\partial_{z_{n}} \bar{u}$ and $\overline{u^{\prime} w^{\prime}}$ cancel and change sign. Therefore, $P_{M}^{e}$ may be negligible in this region. For the only point of measurement we have in this transition zone $\left(z_{n}=1.77 \mathrm{~m}\right)$, mechanical shear production of TKE $P_{M}^{e}$ is negative even because $\overline{u^{\prime} w^{\prime}}$ changes sign above $\partial_{z_{n}} \bar{u}$ (Fig. 4). Since both mechanical shear and buoyancy destroy TKE, other terms such as the turbulent transport or the pressure transport may play role here (e.g., Giometto et al. 2017), and exchange TKE between internal and external regions, from part to part of this transition region. (Denby 1999). Therefore, caution is needed when using $R_{f}$ in the maximum wind speed region of the jet and more generally when $P_{M}^{e}<0$, as illustrated by the spread of the data for the $1.77-\mathrm{m}$ level.

\subsubsection{Turbulent Stress Richardson Number}

As $\overline{u^{\prime} \theta^{\prime}}$ plays an important role in the description of the turbulence state of the flow along a steep slope (Sects. 4.4, 4.5), in this section we also investigate the stress Richardson number $R_{S}$ as defined in Sect. 2.2 (Fig. 11). For the well-defined inner layer and outer layer of the jet $P_{M}^{S}>0 ; P_{B}^{S}$ is negative, and the effect of buoyancy is to reduce the momentum flux magnitude in the inner layer and in the outer layer of the jets where the Boussinesq hypothesis (Eq. 4) holds. Therefore the mixing coefficient $K_{m}$ is reduced, which implies that turbulent mixing is reduced in these two regions of the katabatic jet. Kaimal and Finnigan (1994) describe flux 
Fig. 11 Flux and stress Richardson numbers at the four measurement levels listed in Table 2. Boxes are computed with the 15 (2-min) segments from the pure katabatic event (19 November 2012 from 1915 to 1945 LT). The rectangles in the boxplots represent the interquartile range, the vertical bar inside it is the median of the data. The light grey area represents the region of maximum wind speed

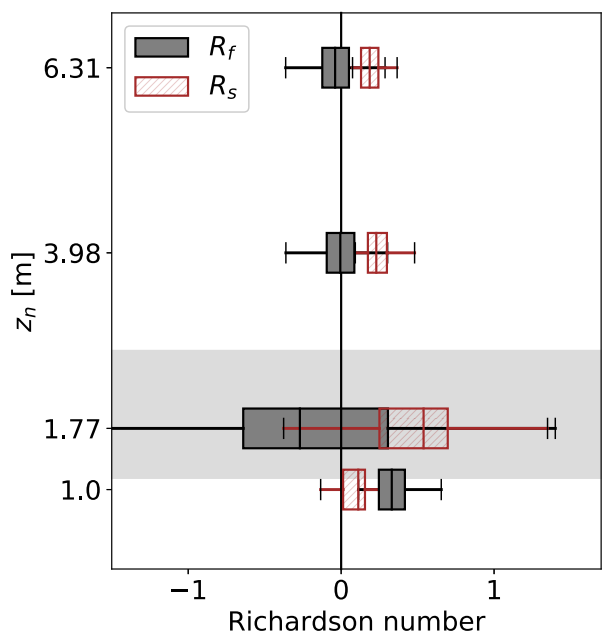

and gradient Richardson numbers as proper parameters for providing a measure of stability in the surface layer. In the present study and in regions where the mean shear is well defined, $R_{S}$ appears as a proper indicator of stability as far as mixing is concerned.

When the mechanical shear term $P_{M}^{S}$ is positive, meaning that $\partial_{z_{n}} \bar{u}$ is negative, the sign of $R_{S}$ is mainly a function of $\overline{u^{\prime} \theta^{\prime}}$ (see Sect. 4.5). The behaviour of $R_{S}$ is thus directly correlated with the profile of the along-slope turbulent sensible heat flux, whose sign is negative in the outer-layer region of the jet and positive below in an idealized katabatic flow (Fig. 5).

In the region around the maximum wind speed, $\partial_{z_{n}} \bar{u}$ becomes zero. TKE (and consequently $\overline{w^{\prime 2}}$ ) also decreases to reach a local minimum (Fig. 5); $P_{M}^{S}$ is minimal and shows a large uncertainty; $R_{S}$ is dominated by the buoyancy contribution $P_{B}^{S}$. The $P_{M}^{S}$ term may even be negative, as is the case for the measurement level at $z_{n}=1.77 \mathrm{~m}$. Parameter $R_{S}$ is not a robust characteristic to describe the effect of buoyancy in the katabatic jet flow for the region of the maximum wind speed. In this transition zone, many quantities change sign, including $\overline{u^{\prime} w^{\prime}}, \partial_{z_{n}} \bar{u}, \overline{u^{\prime} \theta^{\prime}}$, and notable uncertainties surround the value of $\partial_{z_{n}} \bar{u}$, hence explaining the dispersion in the flux and stress Richardson numbers data. Likewise, at the limits of the grey region (whose position is not defined very precisely) in Fig. $11, R_{s}$, as well as $R_{f}$, tend toward infinity.

\section{Summary and Conclusion}

The dataset obtained over a steep slope of more than $20^{\circ}$ with four levels of turbulent measurements up to a height of $6.31 \mathrm{~m}$ allowed us to investigate the impact of buoyancy on TKE following in the footsteps of Grachev et al. (2016) and Oldroyd et al. (2016a). The present study provides a better vertical resolution than previous experimental studies over steep slopes, with one measurement level in the inner-layer region of the jet, one in the region around the maximum wind speed, and two above it, in the outer-layer shear region. Our observations are in agreement with those of Horst and Doran (1988) and Grachev et al. (2016), the analysis presented in Oldroyd et al. (2016a): above $z_{j}$ the buoyancy term of the TKE budget may be positive due to a negative along-slope heat flux. 
We take advantage of the four measurement levels to show that this behaviour is not observed in the inner layer. Instead, the steep slope tends to enhance the consumption of TKE by buoyancy. These conclusions are based on the purest katabatic event extracted from the present data, with nearly no external synoptic forcing and a well-established turbulent flow. We extrapolate our analysis to disturbed katabatic periods, and conclude that even if buoyancy does not always produce TKE above $z_{j}$, it at least reduces its consumption.

Further, the katabatic jet flow is particularly complex in terms of both turbulence intensity and turbulent mixing since, depending on the position along $z_{n}$, the Reynolds stress tensor is profoundly modified by buoyancy effects. We thus supplement the representation of the production of TKE proposed by Oldroyd et al. (2016a) in terms of flux ratio as a function of the slope angle $\overline{u^{\prime} \theta^{\prime}} / \overline{w^{\prime} \theta^{\prime}}(\alpha)$ with the four measurement levels and we extend the same analysis to the production/consumption of $\left|\overline{u^{\prime} w^{\prime}}\right|$. We show that for a katabatic jet over a steep slope, the buoyancy effect is more complex than over a gentle slope. It either destroys or produces TKE and $\left|\overline{u^{\prime} w^{\prime}}\right|$, combined with a situation leading to increased anisotropy in the region around the jet maximum, while decreasing anisotropy above the jet maximum. In the innerlayer region of the jet, the contribution of buoyancy in stable environments is more classical with a reduction of TKE $\left(R_{f}>0\right)$, but has a weak effect on turbulent mixing $\left(R_{s} \approx 0\right)$. In the outer-layer shear region of the katabatic jet, $R_{f}$ is close to neutral value (slightly negative), implying weak buoyancy production of TKE compared with the mechanical production of TKE. The value of $R_{s}$ in this region is positive, which implies reduction of $\left|\overline{u^{\prime} w^{\prime}}\right|$ leading to reduced turbulent mixing. In the region around the maximum wind speed, mechanical shear consumption is observed: $P_{M}^{e} \leq 0$ and $P_{M}^{s} \leq 0$, which disqualifies the standard use of Richardson numbers $R_{f}$ and $R_{s}$.

Acknowledgements This work was supported by a Grant from Labex OSUG@2020 (Investissements d'avenir-ANR10 LABX56). The in-situ measurements were performed in the framework of the LEFE/IDAO program with financial support provided by the French National Institute of Earth Sciences and Astronomy (INSU).

\section{References}

Axelsen SL, van Dop H (2009a) Large-eddy simulation of katabatic winds. Part 1: comparison with observations. Acta Geophys 57(4):803-836

Axelsen SL, van Dop H (2009b) Large-eddy simulation of katabatic winds. Part 2: sensitivity study and comparison with analytical models. Acta Geophys 57(4):837-856

Blein S (2016) Observation and modeling of stable atmospheric boundary layer in complex topography: turbulent processes in katabatic flow. $\mathrm{PhD}$ thesis, Université Grenoble Alpes (in French)

Boussinesq J (1877) Essai sur la théorie des eaux courantes. C R l'Acad Sci 87:1-680

Bradshaw P (1969) The analogy between streamline curvature and buoyancy in turbulent shear flow. J Fluid Mech 36(1):177-191

Brugger P, Katul GG, De Roo F, Kröniger K, Rotenberg E, Rohatyn S, Mauder M (2018) Scalewise anisotropy of the Reynolds stress tensor in the atmospheric surface layer and canopy sublayer. In: EGU general assembly conference abstracts, vol 20, p 8754

Brun C (2017) Large-eddy simulation of a katabatic jet along a convexly curved slope. Part 2: evidence of Görtler vortices. J Geophys Res Atmos 122(10):5190-5210

Brun C, Blein S, Chollet J (2017) Large-eddy simulation of a katabatic jet along a convexly curved slope. Part 1: statistical results. J Atmos Sci 74(12):4047-4073

Burkholder BA, Fedorovich E, Shapiro A (2011) Evaluating subgrid-scale models for large-eddy simulation of turbulent katabatic flow. In: Quality and reliability of large-eddy simulations II. Springer, Berlin, pp $149-160$

Denby B (1999) Second-order modelling of turbulence in katabatic flows. Boundary-Layer Meteorol 92(1):6598 
Denby B, Smeets C (2000) Derivation of turbulent flux profiles and roughness lengths from katabatic flow dynamics. J Appl Meteorol 39(9):1601-1612

Eriksson J, Karlsson R, Persson J (1998) An experimental study of a two-dimensional plane turbulent wall jet. Exp Fluids 25(1):50-60

Fedorovich E, Shapiro A (2009) Structure of numerically simulated katabatic and anabatic flows along steep slopes. Acta Geophys 57(4):981-1010

Giometto M, Katul G, Fang J, Parlange M (2017) Direct numerical simulation of turbulent slope flows up to Grashof number $G r=2.1 \times 10^{11}$. J Fluid Mech 829:589-620

Grachev AA, Leo LS, Di Sabatino S, Fernando HJS, Pardyjak ER, Fairall CW (2016) Structure of turbulence in katabatic flows below and above the wind-speed maximum. Boundary-Layer Meteorol 159(3):469-494. https://doi.org/10.1007/s10546-015-0034-8

Grisogono B, Oerlemans J (2001) Katabatic flow: analytic solution for gradually varying eddy diffusivities. J Atmos Sci 58(21):3349-3354

Grisogono B, Kraljević L, Jeričević A (2007) The low-level katabatic jet height versus Monin-Obukhov height. Q J R Meteorol Soc 133(629):2133-2136

Horst T, Doran J (1988) The turbulence structure of nocturnal slope flow. J Atmos Sci 45(4):605-616

Howell J, Mahrt L (1997) Multiresolution flux decomposition. Boundary-Layer Meteorol 83(1):117-137

Irwin HPA (1973) Measurements in a self-preserving plane wall jet in a positive pressure gradient. J Fluid Mech 61(1):33-63

Jensen DD, Nadeau DF, Hoch SW, Pardyjak ER (2017) The evolution and sensitivity of katabatic flow dynamics to external influences through the evening transition. Q J R Meteorol Soc 143(702):423-438

Kaimal JC, Finnigan JJ (1994) Atmospheric boundary layer flows: their structure and measurement. Oxford University Press, New York

Klipp C (2018) Turbulent friction velocity calculated from the Reynolds stress tensor. J Atmos Sci 75(4):1029_ 1043

Krug D, Holzner M, Lüthi B, Wolf M, Kinzelbach W, Tsinober A (2013) Experimental study of entrainment and interface dynamics in a gravity current. Exp Fluids 54(5):1530

Krug D, Holzner M, Marusic I, van Reeuwijk M (2017) Fractal scaling of the turbulence interface in gravity currents. J Fluid Mech 820:303-324

Largeron Y (2010) Dynamique de la couche limite atmosphérique stable en relief complexe. Application aux épisodes de pollution particulaire des vallées alpines. $\mathrm{PhD}$ thesis, Université de Grenoble

Largeron Y, Staquet C (2016) Persistent inversion dynamics and wintertime PM10 air pollution in alpine valleys. Atmos Environ 135:92-108

Litt M, Sicart JE, Helgason WD, Wagnon P (2015) Turbulence characteristics in the atmospheric surface layer for different wind regimes over the tropical Zongo glacier (Bolivia, $16^{\circ} \mathrm{s}$ ). Boundary-Layer Meteorol 154(3):471-495

Łobocki L (2017) Turbulent mechanical energy budget in stably stratified baroclinic flows over sloping terrain. Boundary-Layer Meteorol 164(3):353-365

Low PS (1990) Katabatic winds in the lower Tamar valley. Tasmania. Il Nuovo Cimento C 13(6):981-994. https://doi.org/10.1007/BF02514786

Lumley JL (1979) Computational modeling of turbulent flows. In: Advances in applied mechanics, vol 18. Elsevier, London, pp 123-176

McNider RT (1982) A note on velocity fluctuations in drainage flows. J Atmos Sci 39(7):1658-1660

Moncrieff J, Clement R, Finnigan J, Meyers T (2004) Averaging, detrending, and filtering of eddy covariance time series. In: Handbook of micrometeorology. Springer, London, pp 7-31

Monti P, Fernando H, Princevac M, Chan W, Kowalewski T, Pardyjak E (2002) Observations of flow and turbulence in the nocturnal boundary layer over a slope. J Atmos Sci 59(17):2513-2534

Nadeau D, Pardyjak E, Higgins C, Huwald H, Parlange M (2013a) Flow during the evening transition over steep alpine slopes. Q J R Meteorol Soc 139(672):607-624

Nadeau D, Pardyjak E, Higgins C, Parlange M (2013b) Similarity scaling over a steep alpine slope. BoundaryLayer Meteorol 147(3):401-419

Nieuwstadt F (1984) Some aspects of the turbulent stable boundary layer. In: Boundary layer structure. Springer, London, pp 31-55

Oldroyd HJ, Katul G, Pardyjak ER, Parlange MB (2014) Momentum balance of katabatic flow on steep slopes covered with short vegetation. Geophys Res Lett 41(13):4761-4768

Oldroyd H, Pardyjak E, Higgins C, Parlange M (2016a) Buoyant turbulent kinetic energy production in steepslope katabatic flow. Boundary-Layer Meteorol 161(3):405-416

Oldroyd H, Pardyjak E, Huwald H, Parlange M (2016b) Adapting tilt corrections and the governing flow equations for steep, fully three-dimensional, mountainous terrain. Boundary-Layer Meteorol 159(3):539565 
Parmhed O, Oerlemans J, Grisogono B (2004) Describing surface fluxes in katabatic flow on Breidamerkurjökull, Iceland. Q J R Meteorol Soc 130(598):1137-1151

Pope SB (2000) Turbulent flows. Cambridge University Press, Cambridge

Poulos G, Zhong S (2008) An observational history of small-scale katabatic winds in mid-latitudes. Geogr Compass 2(6): 1798-1821

Prandtl L (1942) Führer durch die strömungslehre. F Vieweg \& Sohn, Braunschweig

Skyllingstad ED (2003) Large-eddy simulation of katabatic flows. Boundary-Layer Meteorol 106(2):217-243

Smeets C, Duynkerke P, Vugts H (1998) Turbulence characteristics of the stable boundary layer over a midlatitude glacier. Part 1: a combination of katabatic and large-scale forcing. Boundary-Layer Meteorol 87(1):117-145

Smith CM, Porté-Agel F (2014) An intercomparison of subgrid models for large-eddy simulation of katabatic flows. Q J R Meteorol Soc 140(681):1294-1303

Smith CM, Skyllingstad ED (2005) Numerical simulation of katabatic flow with changing slope angle. Mon Weather Rev 133(11):3065-3080

Stiperski I, Calaf M (2018) Dependence of near-surface similarity scaling on the anisotropy of atmospheric turbulence. Q J R Meteorol Soc 144(712A):641-657. https://doi.org/10.1002/qj.3224

Stiperski I, Rotach MW (2016) On the measurement of turbulence over complex mountainous terrain. Boundary-Layer Meteorol 159(1):97-121

Stiperski I, Holtslag AA, Lehner M, Hoch SW, Whiteman CD (2020) On the turbulence structure of deep katabatic flows on a gentle mesoscale slope. Q J R Meteorol Soc 146:1-26

Stull R (1988) An introduction to boundary layer meteorology. Kluwer Academic Publishers, Berlin

Sun J (2007) Tilt corrections over complex terrain and their implication for $\mathrm{CO}_{2}$ transport. Boundary-Layer Meteorol 124(2):143-159

Vickers D, Mahrt L (1997) Quality control and flux sampling problems for tower and aircraft data. J Atmos Ocean Technol 14(3):512-526

Whiteman CD (2000) Mountain meteorology: fundamentals and applications. Oxford University Press, Oxford Wyngaard J (2010) Turbulence in the atmosphere. Cambridge University Press, Cambridge

Wyngaard J, Coté O, Izumi Y (1971) Local free convection, similarity, and the budgets of shear stress and heat flux. J Atmos Sci 28(7):1171-1182 